\title{
11
}

\section{Mammalian Target of Rapamycin (mTOR), Aging, Neuroscience, and Their Association with Aging-Related Diseases}

\author{
Ergul Dilan Celebi-Birand ${ }^{1}$,Elif Tugce Karoglu', Fusun Doldur-Balli ${ }^{2}$ \\ and Michelle M. Adams 1,3
}

\author{
${ }^{1}$ Interdisciplinary Graduate Program in Neuroscience, Bilkent University, Ankara, Turkey ${ }^{2}$ Department of \\ Molecular Biology and Genetics, Bilkent University, Ankara, Turkey ${ }^{3}$ Department of Psychology, Bilkent University, \\ Ankara, Turkey
}

\subsection{INTRODUCTION}

According to the World Health Organization's report, the world population is rapidly aging. The average life expectancy is increasing worldwide and the ratio of the older population (i.e., persons 65 years or older) to the overall population has gotten larger. The number of people over 60 years is expected to increase from 605 million, an estimation made in 2000, to two billion by 2050, and the percentage of the aged population will have doubled from 11 to $22 \%$ [1]. With this rise in average lifespan there is a surge in the amount of age-related cognitive deficits as well as age-associated diseases. This can interfere with an independent lifestyle for the elderly, as well as put a burden on potential caregivers. For instance, the prevalence of age-related dementia, which is a progressive brain disorder, increases with age. There are no definitive therapies against dementia, and informal and formal care cause a burden on society, families, and caregivers for the elderly [2]. Thus, finding appropriate interventions that alter the course of aging-related disorders is quite important.

Aging is defined as a normal physiological process in which gradual deterioration in body functions occurs [3]. Gradual declines in sensory, motor, and cognitive functions are accompanied with brain aging [4]. With the growing number of older people, aging-associated cognitive decline, which is related to cognitive impairments, has become an important issue. A significant loss of learning and memory capacity, decline in visual and hearing abilities, some gastrointestinal tract problems, motor deficits, deterioration of balance control, and fall-related injuries are several clinical problems in the elderly population associated with the aging of the nervous system [5]. Beyond these clinical manifestations, age-related cognitive decline is associated with cognitive dysfunctions, reduced selfsufficiency and loss of independence, which reduce quality of life for older adults [6]. Cognitive capacity decreases during the process of aging even in the absence of a diagnosed pathology. It is a result of multifactorial changes which are combinations of genetic and environmental etiologies [7]. Dissecting the effects of individual factors and revealing the molecular, cellular, and cognitive mechanisms are important in terms of devising restorative interventions for age-related cognitive decline.

In this chapter, we will first provide data on the course of normal versus pathological aging. We will then consider the role of mammalian target of rapamycin (mTOR) signaling in aging, neurological and non-neurological diseases. Taken together, the available data suggest that mTOR signaling may 
underlie the cellular and molecular changes with aging. The potential for factors such as the mTOR pathway to impact those aging-related behavioral and molecular changes, as well as possible interventions, also are considered.

\subsection{COGNITIVE ALTERATIONS ASSOCIATED WITH NORMAL AGING}

Normal aging is associated with behavioral and cognitive alterations. However, these changes in agerelated cognitive capacities are a multidimensional process; decline across one cognitive domain may not be in parallel with or indicative of a falling-off that would occur in another domain. Therefore, some cognitive abilities may decrease at older age but some cognitive skills are preserved.

The pattern of age-related cognitive decline and alterations differs between pathological and normal aging. Therefore, during the analysis of age-related cognitive decline, considering these two directions of normal versus pathological aging is important (Table 11.1). Cognitive decline and alterations in behavior can occur in attention, learning, memory, and executive functions, as well as language abilities. However, the most common and significant declines are usually observed in the learning and memory domains, whose deficiency affects and reduces the well-being of older adults [8]. Therefore, focusing on specific components of these two cognitive domains including episodic memory, semantic memory, and spatial learning-memory will be important for helping elderly individuals maintain their independence.

Episodic memory is memory for autobiographical events and its retrieval depends on contextual or temporal cues [9] and performance on tasks utilizing this ability declines with normal aging $[10,11]$. In, addition to poor episodic memory abilities during older ages, functional magnetic resonance imaging studies revealed that older adults show a different pattern of hippocampal formation and parahippocampal activity during the episodic memory tasks when they are compared with the young control group, and these age-related alterations in the hippocampal and parahippocampal activities may play a role in the age-related decline in episodic memory [12] (Figures 11.1 and 11.2). In the pathological aging conditions, people show a larger decline than normal aging groups in terms of episodic memory. Older people with mild cognitive impairment [13] and people with Alzheimer's disease (AD) show poorer performance in episodic memory tasks than their healthy old group counterparts [9]. In terms of neural activity, older people with AD show a more widespread and decreased activity than the healthy older group, with observations of changes in the posterior cingulate and hippocampal formation [14]. These activity alterations could account for the performance differences between normal and pathological aging.

Semantic memory, which is referred to as acquired knowledge and concepts independent from contextual cues like the meaning of the words and geographical facts, is another component of memory [9]. Unlike the episodic component of the memory domain, agerelated cognitive decline is not so evident in semantic memory [15]. Experimental evidence suggests that there may be some decline but it is not necessarily a linear one since it is has been shown that 55- to 60-year-old people tend to show better performance in semantic memory tasks than the younger and older controls [11]. Also, in terms of brain activity, neural activity dedifferentiation found in episodic memory tasks is not found in semantic memory tasks between old and young groups, which indicates that the course of activation required for semantic memory is similar between young and old groups [16]. Therefore, based on these findings it could be concluded that semantic memory is preserved during normal aging. On the other hand, in the pathological aging conditions like $\mathrm{AD}$, this preserved pattern is not observed and there is an evident decline in semantic memory [17]. The differences in performance in semantic memory tasks between $\mathrm{AD}$ and normal aging are likely explained by the volume loss in left medial perirhinal cortex, entorhinal cortex, and hippocampal formation [18].

Spatial learning and memory are components of the learning and memory domains in which particular locations are associated with distinct stimuli or cues, and these stimuli are used to learn the location of the object of interest. This process requires both learning and memory abilities [19]. In different animal models [20-23] and human studies [24,25], it has been demonstrated that the performance related to spatial learning and memory reduces with normal aging. Older groups tend to show poor spatial learning and memory ability when they are compared with young groups in related tasks including the radial maze, Morris water maze, virtual maze, and so forth. It has been suggested that age-related deficits in spatial memory are associated with hippocampal integrity and during aging as hippocampal function declines, spatial learning and memory deficits begin to occur $[20,23]$. In terms of comparisons between normal and pathological aging conditions, it has been shown that older people with Lewy body dementia and $\mathrm{AD}$ tend to show worse performance in spatial learning and memory-related tasks when compared to healthy old groups, and people with Lewy body dementia tend to show more 
TABLE 11.1 Summary of the Molecular, Cellular, and Behavioral Findings Associated with Cognitive Deficits, and Effects of mTOR Manipulations in Normal and Pathological Brain Ageing Conditions

\begin{tabular}{llll}
\hline $\begin{array}{l}\text { Findings } \rightarrow \\
\text { Conditions } \downarrow\end{array}$ & Neural loss & Molecular alterations & Behavioral alterations \\
\hline Normal aging & No neural loss & $\begin{array}{l}\text { Subtle changes in } \\
\text { synaptic integrity }\end{array}$ & $\begin{array}{l}\text { Decline in domains including spatial } \\
\text { learning-memory, episodic memory }\end{array}$
\end{tabular}

Parkinson's disease
Dopaminergic neural loss especially in substantia nigra pars compacta
Deficits in dopaminergic circuitry

\section{learning-memory, episodic memory}

\begin{abstract}
Alzheimer's disease

Neural loss especially hippocampus and cerebral neocortex
\end{abstract}

Frontotemporal Neural loss in frontal dementia and temporal lobes accumulation

- Presence of neurofibrillary tangles

- Hyperphosphorylated tau protein
- Amyloid-beta protein
Proteinopathies including TDP-43
Effects of mTOR manipulations

Partial inhibition by rapamycin

- Decreased levels of IL-1 $\beta$

- Increased NMDA signaling

- Augmented monoamine levels

- Better cognitive performance

Partial inhibition by rapamycin and ataxia

- Anxiety and depression

Deficits across domains including memory, spatial learning, language, attention, visual perception, executive functions, and social function

- Suppressed PD-related pathological phenotype, this suppression is mediated by 4EBP activity

- Ameliorated PD-related mitochondrial defects

- Protective against PD-related neural death

PD mimetics

- Inhibited mTOR pathway

- Neural loss

Inhibiton of all actions of mTOR by Torin 1

- Not protective against PD

- Induced neural death

Partial inhibition by rapamycin

- Better spatial learning and memory

- Reduced amyloid-beta levels

- Induced autophagy in hippocampus

- Abnormal social behavior and apathies

- Cognitive deficits in executive function, attention, visuospatial abilities, language, and memory

Partial inhibition by rapamycin

- Reduced decline in learning and memory

- Reduced neural loss

- Decreased levels of TDP-43 products

Partial inhibition by rapamycin

- Protection against neural death and toxicity

- Decreased protein aggregation

- Reduced motor and behavioral deficits 


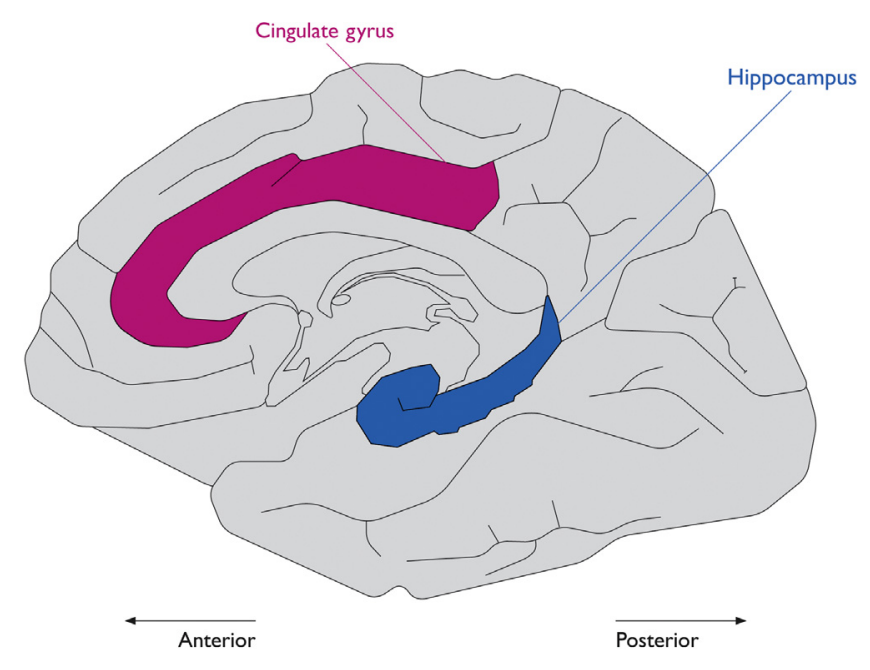

FIGURE 11.1 Human brain medial view. A schematic drawing illustrating the medial view of the human brain. Hippocampus, found in the medial temporal lobe and cingulate gyrus, positioned in parts of the frontal and parietal lobes, are highlighted. In this view, the anterior part of the brain is towards the left and the posterior to the right.

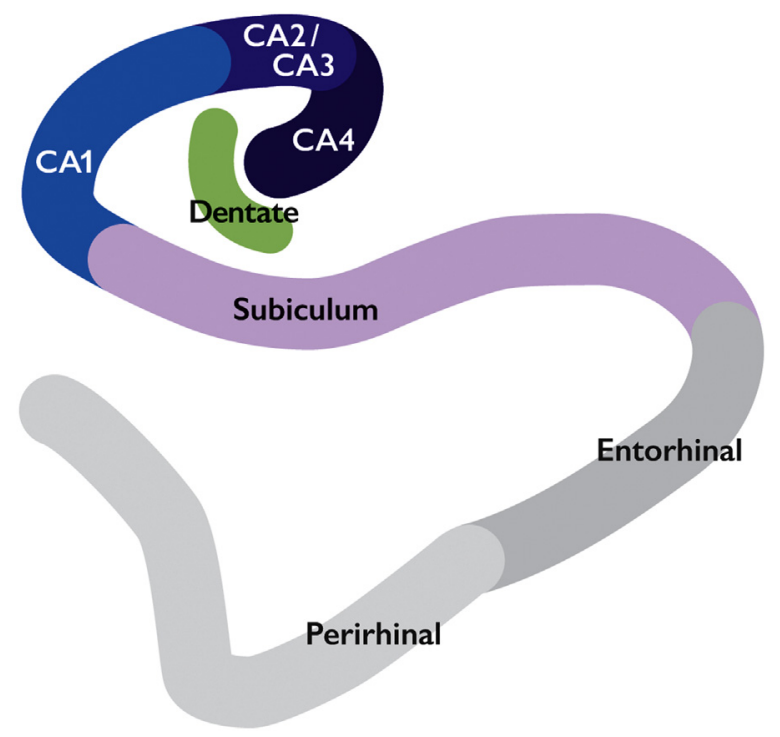

FIGURE 11.2 Hippocampus and parahippocampal gyrus. A schematic diagram showing the hippocampal regions CA1, CA2/ CA3, CA4, dentate gyrus, entorhinal and perirhinal cortices (parahippocampal gyrus). CA1, CA3, dentate gyrus, entorhinal and perirhinal cortices are affected regions both in normal and pathological aging conditions, and their aberrant functioning is likely to underlie learning and memory deficits in the elderly.

cognitive deficits in spatial memory than people with AD [26]. Therefore, although some cognitive abilities decline with normal aging, this impairment becomes more severe during pathological aging.

\subsection{CELLULAR AND MOLECULAR ALTERATIONS ASSOCIATED WITH NORMAL BRAIN AGING}

Determining the cellular and molecular changes that are occurring in the aging brain and underlie cognitive decline is key to determining the targets for possible interventions. Early studies suggested that age-related cognitive decline is a result of significant cell $[27,28]$ and synapse loss $[29,30]$, but subsequent studies using unbiased counting techniques have shown that overall loss of cells [31-33] and synapse $[34,35]$ associated with aging was not observed. Instead, it has been proposed that subtle changes in synaptic integrity rather than large-scale alterations are likely to underlie age-related cognitive decline [7]. For example, there is an age-related decline in axospinous-type synapses in the dentate gyrus of the hippocampus, a structure that is integrally linked to learning and memory $[30,36]$. In the hippocampus, Smith et al. reported no changes in synaptophysin levels, a key synaptic protein, between young and old rats, however, when the aged animals were separated according to their memory ability, they found decreases in synaptophysin levels for behaviorally impaired old rats in the molecular layer of the dentate gyrus and the lacunosum-moleculare layer of CA3 [37] (Figure 11.2). Thus, unlike pathological aging that is associated with a disease state, it is likely that there are very subtle region- and layer-specific age-related changes in synapses during normal aging, suggesting the importance of examining other aspects of synapses which may also be changing with age.

Multiple factors may be affecting the function of synapses in the aging brain. For example, brain-derived neurotrophic factor (BDNF), which is a neurotrophin family member and a mediator of synaptogenesis, synaptic plasticity, neuronal survival, and differentiation in the mammalian brain [38,39] is another factor that is related to cognitive aging. Age-related learning impairments were reported in a study which used a heterozygous BDNF knockout mouse model [40].

Neurogenesis, which is a process required for maintenance of cellular turnover and cognitive plasticity in adult brains, was shown to decrease dramatically in the subventricular zone (SVZ) of the forebrain lateral ventricles of old rodents. SVZ is the main source of neural stem cells. The major decline was detected during the transition from young age to middle age [41]. Since newborn granule cells are proposed to be involved in pattern separation [42], drastic decreases in neurogenesis at old age might be related to cognitive decline from this aspect [43]. The endocannabinoid system functions in neuroprotection, regulation of neurogenesis, and BDNF expression [43,44]. This system is 
involved in the aging process and indeed mutant mice lacking cannabinoid 1 (CB1) receptor performed much worse in several learning and memory tests as aging progressed $[45,46]$. These findings indicated an accelerated cognitive aging phenotype associated with the deletion of the CB1 receptor gene, and further research proposed an age-related function for CB1 receptor on cortical glutamatergic neurons in habituation and acquisition of spatial learning [44].

In terms of gene expression profiles that are altered with increasing age, the most affected gene expression profiles are those whose functions are involved in calcium signaling and the cyclic adenosine monophosphate response element-binding protein pathway [47], synaptic plasticity, mitochondrial function, stress response, DNA repair, and inflammation [48,49]. A gene expression study in which young and old male and female zebrafish brains were compared found that neurogenesis, cell differentiation, and development of brain- and nervous-system-related genes are differentially expressed [50]. Epigenetic regulations depending on histone modifications are also associated with the aging process [51,52]. Since changes in the chromatin structure lead to outcomes at the transcriptional level, they may result in alterations of the hippocampal gene expression and eventually may impair cognitive functions [53]. Alterations in the expression of genes that function in inflammation and apoptosis are accelerated in neurodegenerative diseases [43].

A key molecular target that may contribute to age-related cognitive decline is the glutamate receptor. Glutamate receptors are the primary mediators of excitatory transmission in the central nervous system [54], and play an important role in learning and memory, connecting them to age-related decline $[55,56]$. In the adult hippocampus, the primary types of glutamate receptors are $N$-methyl-D-aspartate (NMDA) and alpha-amino-3-hydroxy-5-methyl-4-isoxazole propionic acid (AMPA). Each of the pharmacologically defined classes of ionotropic glutamate receptors are composed of multimeric assemblies of protein subunits [54]. The critical subunits for NMDA receptors are NR1, NR2A, and NR2B, and for AMPA receptors are GluR1 and GluR2. Families of subunits are recognized by sequence homology $[54,57,58]$ and supported by coprecipitation studies revealing distinct subunit assembly patterns $[59,60]$, and common electrophysiological and pharmacological properties demonstrated in expression systems [54,61,62]. Finally, glutamate receptors have been linked to learning and memory such that decreases in levels lead to memory impairments [63] and increases lead to memory enhancement [64].

Glutamate receptors, in particular the NMDA receptor, have been implicated in age-related cognitive decline [65-67]. Age-related changes in glutamate receptor levels have been observed in many studies, although the data are equivocal as to the direction of change. Although age-related decreases in NMDA receptor levels, specifically in NR1 and NR2B, have been described in some studies [68,69], there are studies with contradictory results that show no changes [70]. Additionally, age-related decreases in the AMPA receptor subunits GluR1 and GluR2 levels have been reported in all the subfields of the rat hippocampus [71]. In addition to the molecular alterations, functional changes in excitatory transmission mediated by glutamate receptors have been reported in the aging hippocampus. For example, long-term potentiation (LTP), an NMDA receptor-dependent plasticity mechanism, and a model of cellular learning and memory, has been shown to have a faster rate of decay in aged animals [65]. The threshold for induction of LTP is elevated in aged rats [72], and the late phase of LTP has been found to be significantly reduced in aged mice [23]. Moreover, there is a shift in LTP from being an NMDA-dependent mechanism to one that is dependent on voltage-dependent $\mathrm{Ca}^{2+}$ channels in hippocampal CA1 of aged rats [73]. Additionally, there is a significant reduction in both NMDA and non-NMDA glutamate receptor-mediated excitatory postsynaptic potentials in CA1 of 27-month-old rats as compared to 9-month-old rats [74]. Finally, the magnitude of LTP is reduced in the aged animals $[68,69]$. Thus, these data suggest that glutamate receptor changes, particularly NMDA receptors, may contribute to age-related declines in cognitive function.

In the brain, the astroglia interact very closely with glutamatergic synapses forming what is called the tripartite synapse. It is becoming clear that astroglia play a very important role in synaptic transmission in addition to their role as a trophic support for neurons. They integrate and process synaptic information and control synaptic transmission and plasticity [75]. While the primary focus of aging-related research has been on alterations in excitatory synapses that contribute to age-related cognitive decline, very little work has been done on the contribution of glial changes during aging and our knowledge is rudimentary at best. It is well established that as there are changes in excitatory synapses, there are parallel changes in glial cells. For example during the estrous cycle there are fluctuations in the circulating levels of estrogen. In the rodent hippocampus, it is well-documented that excitatory synapse number increases when estrogen levels are high [76]. Moreover, there is evidence that as the number of these excitatory synapses increases and decreases, the number of astrocytic processes increases and decreases in a concomitant manner $[77,78]$. In the context of aging, there is evidence suggesting that glial 
fibrillary acidic protein (GFAP)-positive astrocytes become fewer, smaller and less complex in the CA1 region of the hippocampus [79]. The level of glutamine synthetase, which is an enzyme that is critical for glutamate homeostasis and is maintained by astrocytes to help neurons produce glutamate, is reduced in the hippocampus but the levels of S100ß, a calciumbinding protein that regulates astrocytic movement and shape, is increased in the aged brain [80]. Beside these findings, our knowledge of glial modifications in the context of aging is still very limited. The age-related changes in glia are more complex than expected, thus, they should be further investigated in relation to alterations in excitatory synapses. Thus, while some of the observations of cellular and molecular changes in the normal aging brain may be similar to those seen in pathological aging, the normal aging brain changes are more subtle in nature despite resulting in cognitive impairments. Differences in the molecular and cellular changes between normal and pathological aging will be discussed further below (Table 11.1).

\section{4 mTOR SIGNALING PATHWAY}

mTOR is a serine/threonine kinase, belonging to the phosphatidyl inositol $3^{\prime}$ kinase-related kinase family [81]. It was named after its sensitivity to rapamycin, an antifungal agent that is synthesized by the bacterial species Streptomyces hygroscopicus [82]. The interaction of rapamycin is an indirect interaction rather than a direct one. Rapamycin forms a complex with cyclophilin protein FKBP12, and this protein-inhibitor complex then binds to the FKBP12-rapamycin-binding (FRB) domain of mTOR (Figure 11.3). This interaction inhibits access to mTOR's active site [83-85]. mTOR homologs have been identified in several non-vertebrate or nonmammalian organisms including budding yeast $[86,87]$, C. elegans, Drosophila, and zebrafish [88-90].

mTOR is found in two distinct protein complexes in the cell: mTOR complex 1 (mTORC1) and mTOR complex 2 (mTORC2). mTORC1 is composed of mTOR, mLST8, DEPTOR, Raptor, AKT1S1/PRAS40, and promotes transcription, translation, cell cycle progression, ribosome biogenesis, and cell growth through repression of autophagy [91,92] (Figure 11.3). mTORC2 is composed of mTOR, mLST8, DEPTOR, Rictor, mSin1 (also known as MAPKAP1), and PRR5 (also known as PROTOR-1) [93,85] (Figure 11.3). mTORC2 regulates cell survival, cytoskeleton, cell cycle, and cell metabolism [92]. Early evidence suggested that rapamycin only inhibited the activity of mTORC1 but not mTORC2, however chronic rapamycin treatment has later been shown to inhibit mTORC2 through binding to free mTOR [94]. mTOR interacts with Akt in both complexes. mTORC1 is indirectly activated by active Akt, whereas phosphorylation of Akt at Ser473 residue via mTORC2 upregulates the overall Akt/ mTOR pathway activity $[95,96]$.

\section{5 mTORC1}

Deregulation of mTORC1 has been implicated in aging, cancer, obesity, type 2 diabetes, and neurodegenerative diseases [97]. mTORC1 is activated in response to nutrients, growth factors, oxygen, energy status of the cell, and inflammation [93]. Active mTORC1 in turn regulates eukaryotic translation and protein synthesis through phosphorylation of S6 kinase 1 (S6K1) and eukaryotic translation initiation factor 4E (eIF4E) binding protein 1 (4E-BP1) $[98,99]$. eIF4E normally binds to the m7GpppN cap located at the 5 '-end of mRNAs. Unphosphorylated 4E-BP1 represses translation, and its phosphorylation via mTORC1 which causes dissociation of 4E-BP1 from eIF4E, and enhances eIF4E-mediated translation. S6K1 regulates protein synthesis, cell growth, and proliferation through an mTORC1-dependent mechanism. mTORC1 phosphorylates and activates S6K1 $[100,101]$. Both S6K and $4 \mathrm{E}-\mathrm{BP}$ proteins contain a common amino acid motif called TOR signaling (TOS) motif, which has been suggested to be essential for interaction with Raptor in mTORC1 [102,103].

Growth factors such as insulin and insulin-like growth factor 1 (IGF1) activate receptor tyrosine kinases (RTKs). Active RTKs induce production of phosphatidylinositol $(3,4,5)$-trisphosphate (PIP3) and activate Akt. Akt exerts its effect on mTORC1 through two mechanisms: inactivating the tuberous sclerosis complex (TSC) via phosphorylation, and inhibiting the interaction of the proline-rich Akt substrate $40 \mathrm{kDa}$ (PRAS40) with mTORC1.

When phosphorylated by Akt, PRAS40 can bind to the 14-3-3 protein. Although the downstream events initiated upon this binding are not clear yet, it has been proposed that binding of the 14-3-3 protein to phosphorylated PRAS40 inhibits it from binding to mTOR, thus relieving inhibition on mTOR [104]. The negative regulation of mTORC1 activity by PRAS40 might be due to inhibition of mTORC1-mediated phosphorylation of 4E-BP1 and S6K1 [105,106].

TSC1 and TSC2, proteins upstream of mTOR identified as tumor suppressors, form heterodimers and act in TSC to inhibit mTOR signaling by converting Ras homolog enriched in brain (Rheb) from guanosine triphosphate (GTP)-bound to guanosine diphosphate (GDP)-bound forms. Rheb can only activate mTOR when it is bound to GTP and farnesylated [107], hence TSC indirectly inhibits mTOR signaling through Rheb [108,109]. Akt phosphorylates TSC2, leading to 


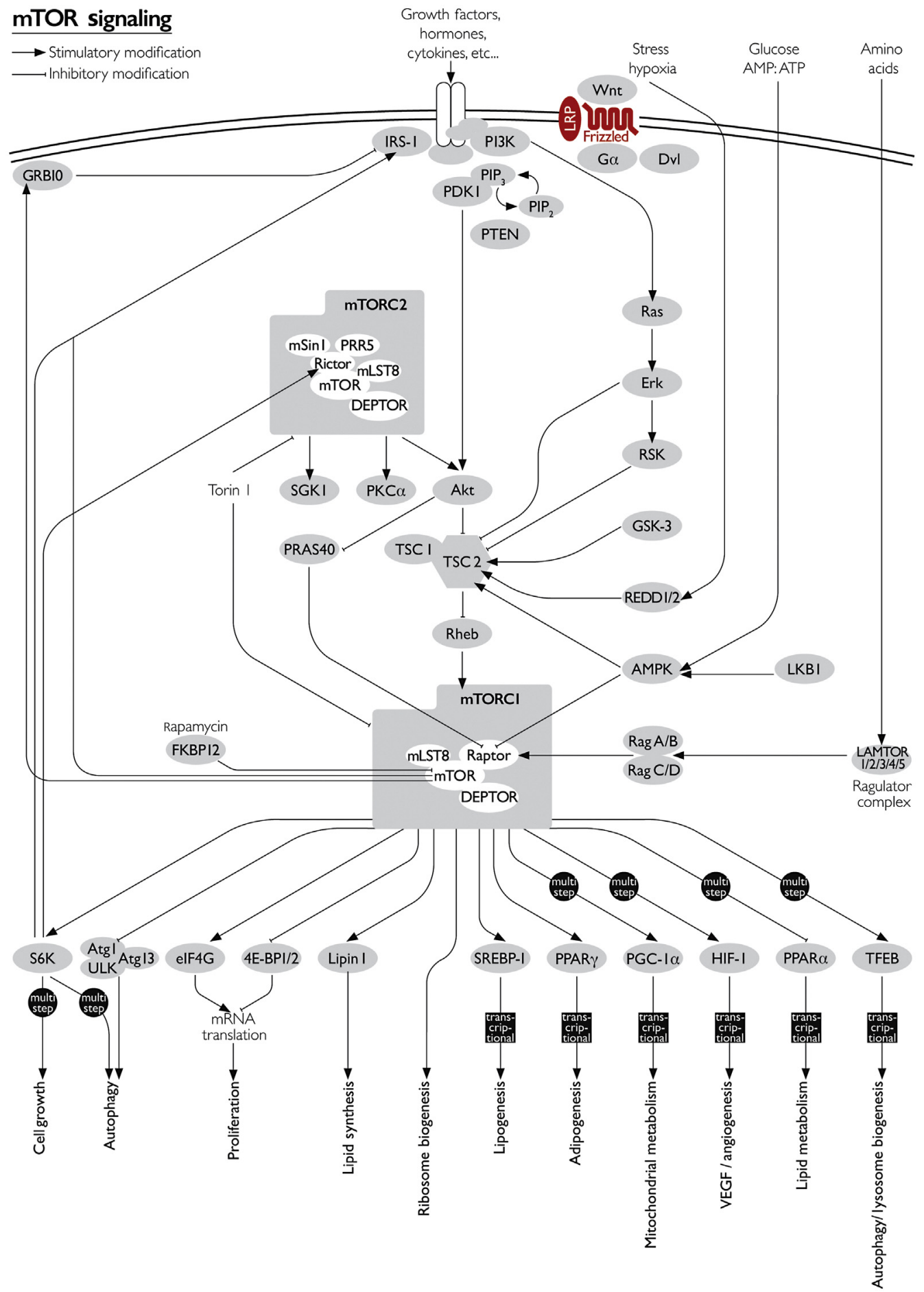

FIGURE 11.3 The mTOR signaling pathway. mTOR is found in two distinct protein complexes: mTORC1 and mTORC2. mTORC1 promotes cell growth through a multistep process mediated by S6K, proliferation by relieving inhibition on eIF4G, lipid synthesis, lipogenesis, and lipid metabolism by activating lipogenic transcription factors Lipin 1, SREBP-1, and PPAR $\alpha$. mTORC1 is also involved in ribosome biogenesis, adipogenesis, angiogenesis, and mitochondrial metabolism, and inhibits autophagic activity through inhibition of Atg1/Atg13/ULK complex. mTORC2's effects on these cellular processes are largely indirect, as mTORC2 exerts most of its effects through mTORC1 and its signaling partners. mTORC1 in turn regulates the activity of mTORC2 through phosphorylation of mSin1 in the mTORC2. 
the disruption of the TSC1-TSC2 heterodimer [110] and relieves repression on mTOR. AMP-dependent protein kinase (AMPK), on the other hand, is activated by serine/threonine kinase LKB1/STK11-mediated phosphorylation, and activates TSC2 in turn through phosphorylation [111,112].

Recently, FKBP38 has been identified as another component of mTORC1. FKBP38 binds to FRB domain of $\mathrm{mTOR}$, the binding site for another protein belonging to the same family: fKBP12. However, unlike FKBP12, FKBP38 does not need rapamycin to bind mTOR. It has been also shown that Rheb-GTP binds to FKBP38 with higher affinity than Rheb-GDP, and active Rheb prevents FKBP38 from binding to mTOR and relieving it from inhibition [113,114]. Yet another study suggested that the interaction of Rheb with FKBP38 did not differ between GTP- or GDP-bound forms [115].

An additional response mechanism of mTOR to cytokines and growth factors has been suggested to involve signal transducer and activator of transcription 3 (STAT3). Phosphorylation of STAT3 at Tyr705 by Janus kinase or RTKs has been shown to facilitate dimerization of STAT3 and the translocation of the dimer to the nucleus. Upon nuclear translocation, STAT3 regulates cell growth, proliferation, and cell survival [116]. Recently, phosphorylation of STAT3 at Ser727 by various kinases including mTOR has been shown. Furthermore, rapamycin was found to reduce phosphorylated STAT3 levels [117], and loss of TSC1 and TSC2 has been linked to increased levels of phosphorylated STAT3, a common observation in several human cancers. Elevated STAT3 activity promotes tumorigenesis by positively regulating the expression of genes that are involved in mechanisms crucial for cancer cells such as cell growth, proliferation, survival, angiogenesis, and metastasis [118].

mTORC1 also promotes tumorigenesis through lipid synthesis, a mechanism required for actively proliferating cells. mTORC1 positively regulates sterol-regulatory-element-binding proteins (SREBPs), transcription factors that control lipogenic genes and their expression [119]. While mTORC1 induces nuclear translocation of active SREBPs, inhibition of mTORC1 reduces SREBP expression at transcriptional and translational levels [93]. The nuclear translocation of SREBPs requires Lipin 1, a transcriptional coactivator that is phosphorylated by mTORC1. Phosphorylated Lipin 1 is translocated out of nucleus, and its exclusion from the nucleus relieves SREBPs from suppression. Free SREBPs then bind to target genes involved in lipid synthesis [120].

Since growth factors and nutrients regulate adipose tissue accumulation, it is not surprising that mTORC1 has a role in adipogenesis. Indeed, mTORC1 inhibition has been shown to have severe effects on adipogenesis and maintenance of adipose cells [93]. mTORC1 exerts its positive effects on adipogenesis indirectly, through peroxisome proliferator-activated receptor $\gamma$ (PPAR $\gamma$ ). PPAR $\gamma$ controls expression of genes involved in fatty acid synthesis and processing [121].

A related protein, PPAR $\alpha$, regulates genes that are involved in hepatic ketogenesis and fatty acid oxidation. Evidence suggests that mTORC1 inhibits PPAR $\alpha$ activity by recruiting its negative regulator, nuclear receptor corepressor into the nucleus [122]. Interestingly, mTORC1 activity has been shown to be increased in the livers of old mice [123], suggesting a link between metabolism, aging, and mTORC1.

mTORC1 signaling has been shown to influence proinflammatory processes and neo angiogenesis through induction of hypoxia-inducible factor $1 \alpha$ (HIF1 $\alpha)$ [124]. Cancer cells often have to cope with oxygen deprivation, and HIF1 $\alpha$ promotes expression of genes that shift cellular energy metabolism from aerobic to anaerobic respiration and regulates glycolysis and glucose transport [125]. mTORC1 positively regulates HIF1 $\alpha$ through 4E-BP1-eIF4-dependent translational activation. The HIF1 $\alpha-$ MTORC1 axis is also involved in angiogenesis and promotes tumorigenesis [93].

In addition to growth factors, amino acids are crucial for activation of mTORC1. A recent study proposed an inside-out model of amino acid sensing. According to this model, amino acids accumulate in the lysosomal lumen, and this accumulation initiates a signaling cascade that involves vacuolar $\mathrm{H}^{+}$-adenoside triphosphate ATPase (v-ATPase). The interaction of v-ATPase with Ragulator at the lysosomal surface recruits mTORC1 to the lysosome. Ragulator is a protein complex that is essential for amino-aciddependent activation of mTORC1 [126]. The Ragulator complex has guanine nucleotide exchange factor activity on Rag GTPases, through which mTORC1 is recruited to the lysosomal surface. Upon amino acid stimulation, RagA or RagB, both Rag GTPases, interacts with Raptor in mTORC1 [127]. This recruitment allows mTORC1 to interact with Rheb since Rheb resides at the lysosomal surface.

mTORC1 regulates cellular homeostasis in several ways. One way is modulation of autophagy. Selfdegradation of proteins, and even entire organelles, is achieved through formation of the autophagosome. This process is crucial for clearance of damaged, dangerous, or toxic particles from the cell. mTORC1 is a known suppressor of autophagy. Studies in yeast and mammals suggested that mTORC1 phosphorylates autophagy-related proteins Atg1 and Atg13 found in a complex that is essential for autophagosome formation. Phosphorylation by mTORC1 disrupts 
the complex and inhibits the activation of the autophagic pathway. In mammals, in addition to Atg1 and Atg13 proteins, an Atg homolog named ULK is negatively regulated by mTORC1, indicating a conserved mechanism for mTORC1-mediated regulation of autophagy [128].

Finally, lysosome biogenesis and its modulation by the mTORC1-TFEB (transcription factor EB) axis is an important regulator of cellular homeostasis. Lysosomes are responsible for lipid homeostasis, clearance of proteins and organelles, energy metabolism, stress response, and pathogen defense [129]. mTORC1 is one of the key molecules regulating TFEB, which in turn promotes formation of autophagosomes and their fusion with lysosomes [130]. Phosphorylation of TFEB by mTORC1 upon activation of the nutrient-sensing pathway, allows 14-3-3 protein to bind TFEB and inhibit it from translocating to the nucleus. As lysosomal dysfunction is implicated in aging and age-related diseases, such as cancer and neurodegeneration, inhibition of mTORC1 is considered as a potential therapeutic approach [93].

\section{6 mTORC2}

In contrast to substantial evidence emerging on the signaling cascades involving mTORC1, less is known about upstream and downstream components of the mTORC2 signaling cascade. It is known that mTORC2 is insensitive to nutrients or energy status of the cell but sensitive to growth factors and insulin [131]. Insulin has been suggested to facilitate mTORC2 binding to ribosome through a poorly understood PI3K-dependent mechanism [132]. Recent evidence suggests an interplay between mTORC1 and mTORC2 in response to insulin stimulation, and their regulatory role in insulin receptor substrate 1 (IRS-1) degradation through growth factor receptor-bound protein 10-dependent mechanism [133,134]. When active, mTORC2 is involved in cell survival, cytoskeleton organization, and cellular metabolism [97].

The best-characterized role of mTORC2 is phosphorylation of Akt at the Ser473 residue, a posttranslational mechanism required for full Akt activation [96]. This mTORC2-dependent phosphorylation of Akt links mTORC2 to the mTORC1 signaling pathway. However, studies in which mTORC2 is knocked out or knocked down suggest that mTORC2 function is not essential for mTORC1 activity [135]. mTORC1 might indirectly inhibit mTORC2 activity through phosphorylation of mSin1 by S6K1 [136]. Other substrates of mTORC2 are identified as serum- and glucocorticoidinduced protein kinase 1, protein kinase C (PKC) isoforms (in particular, $\mathrm{PKC} \alpha$ ). The former is involved in ion transport and cell growth, while the latter links mTORC2 to cytoskeleton organization [97].

As we have mentioned earlier, recent studies provide evidence of the inhibition of mTORC2 activity upon long-term rapamycin treatment. A model involving dephosphorylation of mTORC2 components $\mathrm{mSin} 1$ and Rictor, and subsequent dissociation of mTORC2 in response to rapamycin was proposed to explain rapamycin's inhibitory effect on mTORC2 [137]. Similar to mTORC1, the TSC1-TSC2 heterodimer was found to be associated with mTORC2. However, this interaction was independent of Rheb, indicating distinct regulatory mechanisms acting on both mTOR complexes. Furthermore, while TSC has an inhibitory effect on mTORC1, it activates mTORC2 [138]. Some recent studies propose the association of mTORC2 with ribosomes, and an endoplasmic reticulum (ER) subcompartment called mitochondrial-associated ER membrane (MAM) in response to growth factor stimulation. It seems that mTORC2 is required for maintenance of MAM, regulation of mitochondrial metabolism and cell survival, although these claims remain to be further explored [132,139,140].

\section{7 mTOR SIGNALING AND AGE- RELATED DISEASES}

The main focus in the last decade has been on mTOR and its relationship to lifespan and disease prevention. It is clear from a large amount of evidence that mTOR overactivation promotes aging and disease, which in turn reduces lifespan [97]. By contrast, blocking mTOR retards aging and disease progression, and significantly increases lifespan. Less work has been performed about the role of mTOR in brain aging and disease but evidence from the role mTOR signaling plays in non-neurological disorders indicates that it could alter the course of normal and pathological brain aging.

\subsection{1 mTOR and Metabolic Diseases}

The mTOR signaling pathway is a nutrient-sensing pathway, meaning that it is regulated by nutrients and several other stimuli, and when activated, it influences cellular processes that have vast effects from metabolism to growth and cellular survival to aging [97]. Owing to its close relation with metabolic processes, mTOR is involved in several metabolic diseases, including diabetes mellitus. Diabetic complications, such as insulin resistance, have been linked with overactivation of the mTOR pathway [124]. Overactivated mTOR has been shown to cause insulin 
resistance, partly due to activation of S6 kinase (S6K) via active mTOR and subsequent degradation of IRSs. This feedback loop renders insulin signaling impaired [134].

In relation to diabetic complications, the mTOR signaling pathway has also been shown to regulate pancreatic $\beta$-cell proliferation and total $\beta$-cell mass [141]. Progressive pancreatic $\beta$-cell loss is a common characteristic of type 1 and type 2 diabetes [142]. Inhibition of mTORC1 via rapamycin treatment only abolished glucose-stimulated $\beta$-cell expansion, but not lipid-induced expansion in zebrafish. The latter has been shown to require insulin/IGF1 signaling, and in combination with the mTOR pathway, they exerted their nutrient-sensing effects that promote pancreatic $\beta$-cell neogenesis. These findings suggested a distinct role for mTOR signaling in progression of diabetes and diabetic complications [143].

The vascular endothelial dysfunction and its most common consequence, cardiovascular diseases, are associated with advancing age. In one study, arteries of older mice, which displayed endothelial dysfunction, have been shown to harbor increased mTOR signaling. SIRT-1, AMPK-1, and mTOR signaling pathways have been shown to be linked to the vascular aging phenotype and several studies suggest that their convergence and crosstalk rather than their independent activities affect vascular endothelial cells. Inhibition of mTOR by rapamycin or rapamycin analogs such as life-long caloric restriction (CR) prevents increased arterial mTOR signaling, improves nitric oxide amounts and ergo, prevents endothelial dysfunction in old mice [144].

\subsection{2 mTOR and Cancer}

There is emerging evidence that cancer is an agerelated disease, and reduced or delayed carcinogenesis is associated with slow, healthy aging. The incidence of common cancers, such as lung, colon, breast, prostate, pancreatic, thyroid, gastric, and brain, increases with age. Not surprisingly, people who live more than 90 years are protected from cancer. Furthermore, a similar pattern has been shown in several animal models such as mice and rats. In long-lived mice and rats, cancer prevalence is very low despite high levels of oxidative stress [145].

The PI3K/Akt/mTOR pathway is among the most frequently altered pathways in human cancers. This may be due to its control over processes that are crucial for tumorigenesis, such as cell cycle progression, cell survival, cellular metabolism and energetics, and transcription [146]. Activation or aberrant functioning of the mTOR pathway by either activation of oncogenes such as Ras, Raf, MEK, PI3K, and Akt or loss of tumor suppressors such as PTEN, NF-1, and P53 has been reported by several research groups studying human cancers [147,128,148,149]. Mutations in the genes encoding the proteins involved in this pathway have been implicated in various cancers. Although mutations that have been identified affect upstream elements such as PTEN [150], PIK3CA [151], PIK3R1 [152] and Akt [153], rather than directly targeting mTOR, aberrant functioning of this pathway is clearly involved in cancer development, and particularly in ovarian cancer [146].

There are several aspects of tumorigenicity on which mTOR has direct or indirect effects. The mechanism through which mTOR is acting is translation initiation, which is required for normal cell growth and proliferation. When aberrant, translational control leads to uncontrolled growth of the cell. Eukaryotic translation initiation is regulated by eukaryotic initiation factors eIF4G, eIF4E, eIF4A, and eIF4F. Of these, eIF4E is regulated by inhibitory eIF4E binding proteins (4E-BPs). 4E-BPs mainly act via binding to eIF4E and inhibiting its association with eIF4F, and therefore lowering translation levels. However, when phosphorylated by active mTOR in the mTORC1 complex upon mitogenic stimulation, 4E-BP1 dissociates from eIF4E, allowing it to form the translation initiation complex and proceed with the translation process [154-156].

Growth factors such as insulin and nutrients regulate mTORC1 activity via activation of the PI3K/Akt pathway [128], and the overexpression of growth factor receptors such as insulin-like growth factor receptor and human epidermal growth factor receptor 2 may activate the PI3K/Akt and mTOR pathways [157]. mTORC2, on the other hand, affects tumorigenesis through its role in glucose metabolism, organization of the actin cytoskeleton, and apoptosis in addition to its distinct role in cell growth and proliferation $[96,158]$. A subunit of mTORC2, Rictor, is overexpressed in some cancer types. Rictor overexpression leads to overactive mTORC2 activity, which has been shown to be associated with higher proliferative and invasive potential of tumors $[159,160]$. TSC1 or TSC2 mutations, on the other hand, cause tuberous sclerosis, a familial cancer syndrome which leads to benign tumors but may progress to malignant ones [161].

The close relationship between mTOR, aging, and cancer may be based on the phenomenon called geroconversion. In proliferating cells, cellular growth and cell division are balanced in response to nutrients and growth factors. In aging cells, the mTOR pathway shifts from cellular arrest and quiescence into senescence. In neoplasms and cancers, cellular senescence is overcome and cells start dividing uncontrollably. 
Hence, both mechanisms depend partly on how the mTOR pathway acts and how it is regulated [145].

\subsection{3 mTOR Signaling and Normal and Pathological Brain Aging}

mTOR is expressed at high levels in the brain, mainly in neurons but also in glial cells. It plays an important role in development for neuron survival and growth. In the adult brain, mTOR controls synaptic plasticity and processes that underlie learning and memory [162]. For example, increases in GluR1 levels were shown to be necessary in the dorsal hippocampus of rat for the learning and memory consolidation process around an inhibitory avoidance training and $3 \mathrm{~h}$ after the training. This study also demonstrated that the increase in the level of GluR1 was obtained through the BDNF/mTOR signaling pathway [163]. mTOR contributes to changes in LTP by regulating protein synthesis in the adult brain [162]. Thus, in normal conditions mTOR is necessary for brain function. However, during normal and pathological aging, mTOR signaling may underlie some of the deficits in brain areas controlling learning and memory (Table 11.1).

In terms of normal brain aging, manipulations of the mTOR pathway result in ameliorating effects against age-related decline. It has been shown that partial inhibition of the mTOR pathway by rapamycin extends lifespan in many model organisms. However, another crucial issue is whether this lifespan increase is correlated with preserved cognitive functions in older ages which would normally decline. Studies in mouse models indicate that rapamycin treatment starting at younger ages has an enhancing effect on spatial memory and learning in older ages. It was shown that these ameliorating effects of rapamycin are associated with reduced IL-1 $\beta$, which is a proinflammatory cytokine associated with memory impairments in older adults' levels in the hippocampus, and increased NMDA signaling. However, these enhancing effects on learning and memory are not observed if the rapamycin treatment starts at older ages [164]. Another study indicated that partial and chronic inhibition of mTOR by rapamycin ameliorated both the cognitive and non-cognitive components of behavior in a mouse model. Eight-month-old animals treated with rapamycin showed better performance in terms of spatial learning-memory; and 25-month-old animals treated with rapamycin showed better long-term memory performance, which is related to aversive stimuli when they are compared with non-treated controls. Additionally, non-cognitive components of behavior, such as anxiety and depressive behaviors, which are also observed in older populations, are reduced in rapamycin-treated groups. The mechanism through which this reduction is occurring is thought to be mediated by partial inhibition of mTOR, which results in increased major monoamine levels including epinephrine, norepinephrine, dopamine, and 5-hydroxytryptamine [165]. In conclusion, the data indicate that in the normal aging condition, that is, without pathology, partial inhibition of mTOR could improve cognitive decline and have ameliorating effects on cognitive and non-cognitive components of behavior that decline with normal aging.

To date, more information has been obtained with respect to the mTOR signaling pathway and pathological brain aging. In terms of normal brain aging, several reports suggest that a decreased rate of hippocampal neurogenesis has been associated with cognitive impairment in the elderly, in particular with the learning and memory processes [166]. In the past it was thought that neurons do not regenerate, however, it is clear now that neural stem and/or progenitor cells with the capacity to generate new neurons throughout the lifespan have been found in certain regions of the adult mammalian brain [167]. The fate of hippocampal neural stem cells depends on both the internal signaling pathways and external stimuli, such as growth factors and nutrients $[168,169]$. Different subtypes of neural stem cells are affected differentially by aging. For instance, the number of quiescent hippocampal neural stem cells has a slower rate of decay than the active hippocampal neural stem cells. Although some reports suggest that the total number of hippocampal neural stem cells does not decline with age but rather the number of quiescent hippocampal neural stem cells increases in response to the aging process $[170,171]$, another study showed a significant decline in the number, and the proliferation rate of hippocampal neural stem cells in aging mice. Interestingly, the mTOR signaling pathway activity was shown to be impaired in these cells, and its restoration stimulated the proliferation of hippocampal neural stem cells in the aged mouse brain. Furthermore, inhibition of the mTOR pathway was shown to be sufficient to induce premature aging in the young mice [172].

\subsubsection{Parkinson's Disease}

Parkinson's disease (PD) is a neurodegenerative disease which is characterized by progressive dopaminergic neural loss, especially in substantia nigra pars compacta, and it results in deficits in motor functions including tremors and ataxia [173]. Currently, there is no decisive treatment for $\mathrm{PD}$; one reason is that 
underlying pathology and the etiology of PD are not very well known. However, current studies have revealed associations of neural loss in PD with apoptosis, oxidative stress, DNA damage, mitochondrial dysfunction, aberrant protein aggregation, and endoplasmic reticulum stress [174-176].

Interestingly, studies have also suggested that components of the mTOR pathway could play a role in PD progression and manipulations targeting this pathway may promise therapeutic strategies for PD (Table 11.1). It has been shown that treatment with rapamycin, which is the pharmacological inhibitor of mTOR, suppresses the PD-related pathological phenotype, including muscle degeneration, locomotor activities, and mitochondrial defects, and these effects of rapamycin were mediated by $4 \mathrm{E}-\mathrm{BP}$ activity in the Drosophila melanogaster model of PD [177]. In contrast, it was reported that in vitro models of $\mathrm{PD}$, in which PD was induced by specific toxins, inhibited mTOR activity. In this model inhibited mTOR activity, which is related to increased AMPK and decreased Akt activity, was associated with neural loss [178]. Based on these studies, it may be the case that both inhibition and activation of the mTOR pathway could be associated with PD-related neural death. Another study indicated that selective suppression of the mTOR pathway is protective against PD-related neural death, and it was shown that although rapamycin is an inhibitor of mTOR activity, it spares some activity of mTOR, such as regulation of Akt phosphorylation, while it inhibits other mTOR activities like S6K (also known as p70S6K) activation. Also, in this study when all the actions of mTOR were inhibited, dephosphorylation of Akt and neural death were induced in both in vitro and mouse models of PD [179]. Therefore for $\mathrm{PD}$, it could be argued that some activities of mTOR are essential for the survival of the neurons and others could be harmful for the neurons during the disease progression. Moreover, complete inhibition of mTOR activity may not be protective against neural death in $\mathrm{PD}$, as the protective effect of rapamycin is associated with its selective suppression of mTOR activity.

\subsubsection{Alzheimer's Disease}

Another pathology associated with advanced age is Alzheimer's disease (AD). AD is the most common progressive neurodegenerative disease in the aging population; cognitive deficits can be observed across domains like memory, spatial learning, language, attention, visual perception, executive functions, and social function [180]. Progressive amyloid-beta protein accumulation and presence of neurofibrillary tangles with hyperphosphorylated tau protein are the pathological hallmarks of $\mathrm{AD}$, and they are associated with progressive neural loss [181]. One reason for the accumulation of these harmful proteins that has been proposed is the presence of an altered autophagy response against these toxic substances in the affected cells [182]. Moreover, since there is an established relationship between the mTOR pathway and autophagy, the mTOR pathway has become a target for interventions and manipulations in order to understand its role in AD (Table 11.1). Evidence demonstrates that long-term inhibition of mTOR with rapamycin in the transgenic $\mathrm{AD}$ mouse model reduces and prevents AD-like cognitive deficits; rapamycin-treated transgenic mice show better performance in spatial memory and learning tasks. This inhibition lowers the levels of amyloid-beta protein (A 342$)$ and prevents or delays the onset of $\mathrm{AD}$. Also, it has been shown that autophagy is induced in the hippocampus of rapamycin-treated transgenic mice. However, these ameliorating effects could not be found in wild-type mice treated with rapamycin, hence the effects of rapamycin may depend on the endogenous $\mathrm{A} \beta$ levels in mice [183]. In another study, mTOR was inhibited by rapamycin in 2- and 15-month-old transgenic AD model mice. In 2-month-old mice, this inhibition prevented cognitive decline in learning and memory, increased autophagy, and decreased the levels of $A \beta$, tau, and tangle accumulation by increasing the soluble $\mathrm{A} \beta$ and tau levels, whereas in 15-month-old mice, this inhibition did not change the soluble or non-soluble levels of $\mathrm{A} \beta$ and tau and did not ameliorate cognitive deficits [184]. Taken together, inhibition of mTOR via rapamycin could ameliorate the progression of $\mathrm{AD}$ and $\mathrm{AD}$-related cognitive deficits, but the extent of these effects may depend on the $\mathrm{AD}$ progression.

\subsubsection{Frontotemporal Dementia}

Frontotemporal dementia is an age-related neurodegenerative disease characterized by neural loss in frontal and temporal lobes (Figure 11.1). Clinical manifestations of frontotemporal dementia in response to neural loss in these specific regions are observed as alterations of certain personality traits. These alterations include abnormal social behavior and apathies, and cognitive deficits in executive function, attention, visuospatial abilities, language, and memory [185]. The molecular and cellular alterations underlying the neural loss are related to proteinopathies, which refers to the presence of malformed or abnormal proteins. One of the proteins associated with frontotemporal dementia is TDP-43. TDP-43 is a DNA/RNA-binding protein, found in the cytoplasmic ubiquitin inclusions of the affected cells, 
and plays a role as a main component in the disease progression [186].

Since the neurodegeneration process in frontotemporal dementia is associated with proteinopathies, induction of autophagy in the affected cells has become a focus as a possible intervention. Studies conducted in the mouse model of frontotemporal dementia demonstrated that inhibition of the mTOR pathway by rapamycin prevents motor and cognitive deficits including learning and memory declines, reduces the neural loss and the caspase-3 levels, which is the indicator of the neural death, and decreases levels of TDP-43 products [187] (Table 11.1). Therefore, it is likely that the inhibition of mTOR, which might result in autophagy activation, may be a promising therapeutic approach for age-related neurodegenerative diseases with proteinopathies.

\subsubsection{Huntington's Disease}

Huntington's disease (HD) is an inherited neurodegenerative disease affecting the whole brain, yet some regions, such as the basal ganglia and hippocampus, are more vulnerable. Clinical symptoms include motor dysfunction, muscle rigidity, problems in memory and executive functions, anxiety, and depression. HD is a polyglutamine tract disorder, emerging when the number of CAG repeats in the HTT gene encoding Huntingtin protein exceeds a specific threshold and mutant Huntingtin protein, which has toxic effects, is produced [188]. Alterations due to mutant Huntingtin protein expression are decreased uptake of glutamate and increased NMDA receptor signaling at the striatal excitatory synapses. Decreased levels of BDNF, and altered striatal dopamine and endocannabinoid signaling accompany degeneration in HD [189].

As in the cases of $\mathrm{AD}$ and frontotemporal dementia, abnormal protein aggregation has been observed in HD. Thus, activation of autophagy through the mTOR pathway could have therapeutic effects in HD. In vitro studies conducted with HD models indicated that inhibition of mTOR with small molecule enhancers of rapamycin increased the clearance of the mutant Huntingtin fragments in the affected cells (Table 11.1). Another study using the Drosophila melanogaster model of HD demonstrated that these small molecule enhancers of rapamycin protect against toxicity induced by mutant Huntingtin protein [190]. Other studies in Drosophila melanogaster have supportive findings of rapamycin protection against neural death and toxicity associated with HD, and studies with a mouse model of HD showed that rapamycin treatment reduces the HD-related motor and behavioral deficits and decreased protein aggregation [191]. It could be said that interventions like the rapamycin targeting of
mTOR and the autophagy mechanism could be a promising therapeutic approach and area of research for HD.

\subsection{INTERVENTIONS FOR ALTERING mTOR ACTIVITY}

It has been previously mentioned throughout this chapter that rapamycin treatment, which inhibits mTOR, can alter the course of aging-related diseases and pathologies. Moreover, it appears to have beneficial effects on lifespan and some of the declines associated with aging. There are many studies reporting that rapamycin treatment extends lifespan in various organisms. For instance, rapamycin treatment late in life (at 600 days of age) extended lifespan in both male and female genetically heterogeneous mice [192]. Another study in Drosophila suggested that genes encoded by mitochondrial DNA have influence on the mTOR pathway, and that mTOR inhibition via rapamycin increases mitochondrial respiration and decreases $\mathrm{H}_{2} \mathrm{O}_{2}$ production [193]. Similar studies in yeast suggested reduced TOS due to deletion of TOR1 gene or rapamycin treatment, and modulation of reactive oxygen species by enhancement of the mitochondrial respiration as a possible mechanism for lifespan extension [194,195].

Rapamycin treatment has also been shown to prevent age-related metabolic diseases including obesity [196,197] and diabetic complications such as retinopathy, nephropathy, and coronary disease in animal models and humans [198,196,199]. Rapamycin mimics starvation or CR, depending on the administered concentration. Therefore, it tricks the organism to think that nutrient supply is growing short. Starvation has several metabolic effects including increased gluconeogenesis, ketogenesis, lipolysis, decreased insulin levels, and it leads to insulin resistance [200].

Given the fact that mTOR signaling is almost universally activated in cancer, rapamycin, rapamycin analogs (i.e., rapalogs), and dietary regimens such as $\mathrm{CR}$ have become promising approaches in cancer prevention and treatment [201-203]. Rapalogs, such as temsirolimus and everolimus, are being used as anticancer drugs, the former being the first rapalog approved by FDA for use in humans [204,205]. Although rapalogs are currently being used in numerous clinical trials, their role as anticancer agents remains modest. This modest effect may be due to their lack of toxicity, and hence inability to kill cancer cells at relevant concentrations. Rather, they act to slow down the growth of cancer cells and prove more effective when used in combination with other anticancer drugs. Regardless of their disadvantage as 
anticancer drugs, they are still effective agents for cancer-preventive and antiaging purposes.

Another intervention that may be beneficial is CR, which is thought to act by blocking the mTOR pathway in a manner similar to rapamycin treatment. Even short-term (i.e., 8 weeks) CR had a protective effect on renal cells of the aged rats. Reduced mitochondrial oxidative damage, retardation of renal senescence, and increased autophagic activity have been accompanied by decreased mTOR levels, and increased SIRT-1 and AMPK levels, in these old rats [206]. Of these mechanisms, autophagic activity has particular significance since its decrease during aging has been considered as the underlying mechanism for the accumulation of abnormal/damaged macromolecules. Degradation of long-lived proteins, unfolded or incorrectly folded proteins, and damaged organelles occur through autophagic pathways. Hence, it is essential for maintenance of cellular and organismal homeostasis [207-209].

It is important to point out that both rapamycin and CR have been shown to affect males and females differentially. In one study, tissue- and sex-specific effects of rapamycin on the proteasome-chaperone network have been shown [80]. For instance, levels of proteasome-related chaperones increased more in females than males. Furthermore, brains of rapamycintreated females had higher levels of mTOR pathway proteins (p-mTOR, p-Akt, rpS6, and 4E-BP1), than males and other tissues tested. These results suggest that rapamycin increases proteasome activity in the brains of female mice, compared to other tissues and male counterparts.

Another study showed that short-term CR in male mice shifted the gene expression profile toward a more feminine type. In this microarray-based study, CR has been shown to change expression levels of over 3000 genes involved in hormone signaling, aging, cell cycle, and apoptosis [210]. When the overall life expectancy of males and females is taken into account, i.e., that females of most mammals have a longer lifespan than males, these results seem quite explanatory for both the underlying mechanisms for CR-induced longevity and sex-dependent variations in response to $C R$ and CR mimetics.

Taken altogether, rapamycin, rapalogs, and CR have been shown to have positive effects on various age-related diseases, and to extend overall and healthy lifespan in both animals and humans. Thus, the effects of CR and the CR-mimetic rapamycin on lifespan have been the subject of ongoing research. It will be important to determine the best regimen, either dietary or therapeutic drug dose, for the optimal antiaging effects. Moreover, more research needs to be performed to determine the exact effects of $C R$ and $C R$ mimetics on normal brain aging.

\subsection{CONCLUSION}

Normal aging is accompanied by a range of biological changes, many of which diminish the quality of life and interfere with the ability of the elderly to function unassisted in society. Even in the absence of evident pathology, cognitive function declines during old age and is often reflected as a significant loss of learning and memory ability. Undoubtedly, the biological changes are multifactorial in nature, and are likely caused by a combination of genetic and environmental factors. Nevertheless, understanding the contribution of individual factors to age-related changes in cognitive function would provide important insight into the mechanisms by which such changes occur, as well as suggest strategies for preventing or ameliorating cognitive changes.

The mTOR pathway appears to be a very important target for altering the course of aging-related cognitive decline and diseases that are both neurological and non-neurological in nature. Understanding the exact effects of mTOR on aging as well as the appropriate therapeutic approaches is the subject of ongoing research. Undoubtedly, these data will contribute to our understanding of both normal and pathological aging and how it can be prevented or altered.

\section{Acknowledgment}

We would like to thank Can I. Birand for helping with preparation of the figures. The research being done in the laboratory of Michelle M. Adams is currently supported by an Installation Grant from the European Molecular Biology Organization and the Scientific and Technological Research Council of Turkey (TUBITAK) project number 214S236.

\section{References}

[1] World Health Organisation. WHO ageing and life-course. Ageing Lifecourse; 2013.

[2] Costa N, Ferlicoq L, Derumeaux-Burel H, Rapp T, Garnault V, Gillette-Guyonnet S, et al. Comparison of informal care time and costs in different age-related dementias: a review. BioMed Res Int 2013;2013:1-15.

[3] López-Otín C, Blasco MA, Partridge L, Serrano M, Kroemer G. The hallmarks of aging. Cell 2013;153:1194-217.

[4] Mora F. Successful brain aging: plasticity, environmental enrichment, and lifestyle. Dialogues Clin Neurosci 2013;15:45-52.

[5] Sarlak G, Jenwitheesuk A, Chetsawang B, Govitrapong P. Effects of melatonin on nervous system aging: neurogenesis and neurodegeneration. J Pharmacol Sci 2013;123:9-24.

[6] Thomas W, Blanchard J. Moving beyond place: aging in community. Generations 2009;33:12-17.

[7] Peters R. Ageing and the brain. Postgrad Med J 2006;82:84-8.

[8] Arslan-Ergul A, Ozdemir AT, Adams MM. Aging, neurogenesis, and caloric restriction in different model organisms. Aging Dis 2013;4:221-32.

[9] Salmon DP, Bondi MW. Neuropsychological assessment of dementia. Annu Rev Psychol 2009;60:257-82. 
[10] Mitchell DB, Brown AS, Murphy DR. Dissociations between procedural and episodic memory: effects of time and aging. Psychol Aging 1990;5:264-76.

[11] Nilsson L-G. Memory function in normal aging. Acta Neurol Scand Suppl 2003;179:7-13.

[12] Cabeza R, Daselaar SM, Dolcos F, Prince SE, Budde M, Nyberg L. Task-independent and task-specific age effects on brain activity during working memory, visual attention and episodic retrieval. Cereb Cortex 2004;14:364-75.

[13] Wang Q-S, Zhou J-N. Retrieval and encoding of episodic memory in normal aging and patients with mild cognitive impairment. Brain Res 2002;924:113-15.

[14] Greicius MD, Srivastava G, Reiss AL, Menon V. Default-mode network activity distinguishes Alzheimer's disease from healthy aging: evidence from functional MRI. Proc Natl Acad Sci USA 2004;101:4637-42.

[15] Craik FIM. Memory changes in normal aging. Curr Dir Psychol Sci 1994:3:155-8.

[16] St-Laurent M, Abdi H, Burianová H, Grady CL. Influence of aging on the neural correlates of autobiographical, episodic, and semantic memory retrieval. J Cogn Neurosci 2011;23:4150-63.

[17] Giffard B. The nature of semantic memory deficits in Alzheimer's disease: new insights from hyperpriming effects. Brain 2001;124:1522-32.

[18] Hirni DI, Kivisaari SL, Monsch AU, Taylor KI. Distinct neuroanatomical bases of episodic and semantic memory performance in Alzheimer's disease. Neuropsychologia 2013;51:930-7.

[19] Olton DS, Samuelson RJ. Remembrance of places passed: spatial memory in rats. J Exp Psychol Anim Behav Process 1976;2:97-116.

[20] Fischer W, Björklund A, Chen K, Gage FH. NGF improves spatial memory in aged rodents as a function of age. J Neurosci 1991;11:1889-906.

[21] Herndon JG, Moss MB, Rosene DL, Killiany RJ. Patterns of cognitive decline in aged rhesus monkeys. Behav Brain Res 1997;87:25-34.

[22] Frick KM, Baxter MG, Markowska AL, Olton DS, Price DL. Age-related spatial reference and working memory deficits assessed in the water maze. Neurobiol Aging 1995;16:149-60.

[23] Bach ME, Barad M, Son H, Zhuo M, Lu YF, Shih $R$, et al. Age-related defects in spatial memory are correlated with defects in the late phase of hippocampal long-term potentiation in vitro and are attenuated by drugs that enhance the cAMP signaling pathway. Proc Natl Acad Sci USA 1999;96:5280-5.

[24] Newman MC, Kaszniak AW. Spatial memory and aging: performance on a human analog of the morris water maze. Aging Neuropsychol Cogn 2010;7:86-93.

[25] Moffat S. Age differences in spatial memory in a virtual environment navigation task. Neurobiol Aging 2001;22:787-96.

[26] Sahgal A, McKeith IG, Galloway PH, Tasker N, Steckler T. Do differences in visuospatial ability between senile dementias of the Alzheimer and Lewy body types reflect differences solely in mnemonic function? J Clin Exp Neuropsychol 1995;17:35-43.

[27] Devaney KO, Johnson HA. Neuron loss in the aging visual cortex of man. J Gerontol 1980;35:836-41.

[28] Henderson G, Tomlinson BE, Gibson PH. Cell counts in human cerebral cortex in normal adults throughout life using an image analysing computer. J Neurol Sci 1980;46:113-36.

[29] Bondareff W. Synaptic atrophy in the senescent hippocampus. Mech Ageing Dev 1979;9:163-71.

[30] Geinisman Y, de Toledo-Morrell L, Morrell F. Loss of perforated synapses in the dentate gyrus: morphological substrate of memory deficit in aged rats. Proc Natl Acad Sci USA 1986;83:3027-31.
[31] Haug H, Eggers R. Morphometry of the human cortex cerebri and corpus striatum during aging. Neurobiol Aging 1991;12:336-8; (discussion 352-5).

[32] Rapp PR, Gallagher M. Preserved neuron number in the hippocampus of aged rats with spatial learning deficits. Proc Natl Acad Sci USA 1996;93:9926-30.

[33] Rasmussen T, Schliemann T, Sørensen JC, Zimmer J, West MJ. Memory impaired aged rats: no loss of principal hippocampal and subicular neurons. Neurobiol Aging 1996;17:143-7.

[34] Newton IG, Forbes ME, Linville MC, Pang H, Tucker EW, Riddle DR, et al. Effects of aging and caloric restriction on dentate gyrus synapses and glutamate receptor subunits. Neurobiol Aging 2008;29:1308-18.

[35] Shi L, Adams MM, Linville MC, Newton IG, Forbes ME, Long $\mathrm{AB}$, et al. Caloric restriction eliminates the aging-related decline in NMDA and AMPA receptor subunits in the rat hippocampus and induces homeostasis. Exp Neurol 2007;206:70-9.

[36] Geinisman Y, Berry RW, Disterhoft JF, Power JM, Van der Zee EA. Associative learning elicits the formation of multiple-synapse boutons. J Neurosci 2001;21:5568-73.

[37] Smith TD, Adams MM, Gallagher M, Morrison JH, Rapp PR. Circuit-specific alterations in hippocampal synaptophysin immunoreactivity predict spatial learning impairment in aged rats. J Neurosci 2000;20:6587-93.

[38] Park H, Poo MM. Neurotrophin regulation of neural circuit development and function. Nat Rev Neurosci 2013;14:7-23.

[39] Cunha C, Brambilla R, Thomas KL. A simple role for BDNF in learning and memory? Front Mol Neurosci 2010;3:1.

[40] Petzold A, Endres T. Chronic BDNF deficiency leads to age-dependent impairment in spatial learning Material \& Methods. Neurobiol Learn Mem 2015;120:1-3.

[41] Hamilton LK, Joppé SE, Cochard LM, Fernandes KJL. Aging and neurogenesis in the adult forebrain: what we have learned and where we should go from here. Eur J Neurosci 2013;37:1978-86.

[42] Yassa MA, Stark CEL. Pattern separation in the hippocampus. Trends Neurosci 2011;34:515-25.

[43] Bilkei-Gorzo A. The endocannabinoid system in normal and pathological brain ageing. Philos Trans R Soc B Biol Sci 2012;367:3326-41.

[44] Legler A, Monory K, Lutz B. Age differences in the role of the cannabinoid type 1 receptor on glutamatergic neurons in habituation and spatial memory acquisition. Life Sci 2015;1-7.

[45] Bilkei-Gorzo A, Racz I, Valverde O, Otto M, Michel K, Sastre M, et al. Early age-related cognitive impairment in mice lacking cannabinoid CB1 receptors. Proc Natl Acad Sci USA 2005;102: $15670-5$

[46] Albayram O, Bilkei-Gorzo A, Zimmer A. Loss of CB1 receptors leads to differential age-related changes in reward-driven learning and memory. Front Aging Neurosci 2012;4:1-8.

[47] Burke SN, Barnes CA. Neural plasticity in the ageing brain. Nat Rev Neurosci 2006;7:30-40.

[48] Lu T, Pan Y, Kao S-Y, Li C, Kohane I, Chan J, et al. Gene regulation and DNA damagein the ageing human brain. Nature 2004;429:883-91.

[49] Jiang CH, Tsien JZ, Schultz PG, Hu Y. The effects of aging on gene expression in the hypothalamus and cortex of mice. Proc Natl Acad Sci USA 2001;98:1930-4.

[50] Arslan-Ergul A, Adams MM. Gene expression changes in aging zebrafish (Danio rerio) brains are sexually dimorphic. BMC Neurosci 2014;15:29.

[51] Moroz LL, Kohn AB. Do different neurons age differently? Direct genome-wide analysis of aging in single identified cholinergic neurons. Front Aging Neurosci 2010;2:1-18. 
[52] Cheung I, Shulha HP, Jiang Y, Matevossian A, Wang J, Weng Z, et al. Developmental regulation and individual differences of neuronal H3K4me3 epigenomes in the prefrontal cortex. Proc Natl Acad Sci USA 2010;107:8824-9.

[53] Peleg S, Sananbenesi F, Zovoilis A, Burkhardt S, Bahari-Javan S, Agis-Balboa RC, et al. Altered histone acetylation is associated with age-dependent memory impairment in mice. Science 2010;328:753-6.

[54] Hollmann M, Heinemann S. Cloned glutamate receptors. Annu Rev Neurosci 1994;17:31-108.

[55] Morris RG, Anderson E, Lynch GS, Baudry M. Selective impairment of learning and blockade of long-term potentiation by an N-methyl-D-aspartate receptor antagonist, AP5. Nature 1986;5:774-6.

[56] Bliss TV, Collingridge GL. A synaptic model of memory: longterm potentiation in the hippocampus. Nature 1993;361:31-9.

[57] Hollmann M, O'Shea-Greenfield A, Rogers SW, Heinemann S. Cloning by functional expression of a member of the glutamate receptor family. Nature 1989;342:643-8.

[58] Nakanishi S. Molecular diversity of glutamate receptors and implications for brain function. Science 1992;258:597-603

[59] Brose N, Huntley GW, Stern-Bach Y, Sharma G, Morrison JH, Heinemann SF. Differential assembly of coexpressed glutamate receptor subunits in neurons of rat cerebral cortex. J Biol Chem 1994;269:16780-4.

[60] Puchalski RB, Louis JC, Brose N, Traynelis SF, Egebjerg J, Kukekov V, et al. Selective RNA editing and subunit assembly of native glutamate receptors. Neuron 1994;13:131-47.

[61] Boulter J, Hollmann M, O'Shea-Greenfield A, Hartley M, Deneris E, Maron C, et al. Molecular cloning and functional expression of glutamate receptor subunit genes. Science 1990;249:1033-7.

[62] Keinänen K, Wisden W, Sommer B, Werner P, Herb A, Verdoorn TA, et al. A family of AMPA-selective glutamate receptors. Science 1990;249:556-60

[63] Tsien JZ, Huerta PT, Tonegawa S. The essential role of hippocampal CA1 NMDA receptor-dependent synaptic plasticity in spatial memory. Cell 1996;87:1327-38.

[64] Tang YP, Shimizu E, Dube GR, Rampon C, Kerchner GA, Zhuo M, et al. Genetic enhancement of learning and memory in mice. Nature 1999;401:63-9.

[65] Barnes CA. Normal aging: regionally specific changes in hippocampal synaptic transmission. Trends Neurosci 1994;17:13-18.

[66] Morrison JH, Gazzaley AH. Age-related alterations of the $\mathrm{N}$-methyl-D-aspartate receptor in the dentate gyrus. Mol Psychiatry 1996;1:356-8.

[67] Morrison JH, Hof PR. Life and death of neurons in the aging brain. Science 1997;278:412-19.

[68] Clayton DA, Mesches MH, Alvarez E, Bickford PC, Browning MD. A hippocampal NR2B deficit can mimic age-related changes in long-term potentiation and spatial learning in the Fischer 344 rat. J Neurosci 2002;22:3628-37.

[69] Eckles-Smith K, Clayton D, Bickford P, Browning MD. Caloric restriction prevents age-related deficits in LTP and in NMDA receptor expression. Brain Res Mol Brain Res 2000;78:154-62.

[70] Adams MM, Shah RA, Janssen WG, Morrison JH. Different modes of hippocampal plasticity in response to estrogen in young and aged female rats. Proc Natl Acad Sci USA 2001;98:8071-6.

[71] Pagliusi SR, Gerrard P, Abdallah M, Talabot D, Catsicas S. Age-related changes in expression of AMPA-selective glutamate receptor subunits: is calcium-permeability altered in hippocampal neurons? Neuroscience 1994;61:429-33.

[72] Barnes CA, Rao G, Houston FP. LTP induction threshold change in old rats at the perforant path-granule cell synapse. Neurobiol Aging 21:613-0.
[73] Shankar S, Teyler TJ, Robbins N. Aging differentially alters forms of long-term potentiation in rat hippocampal area CA1. J Neurophysiol 1998;79:334-41.

[74] Barnes C, Rao G, Shen J. Age-related decrease in the N-Methyld-AspartateR-mediated excitatory postsynaptic potential in hippocampal region CA1. Neurobiol Aging 1997;18:445-52.

[75] Perea G, Navarrete M, Araque A. Tripartite synapses: astrocytes process and control synaptic information. Trends Neurosci 2009;32:421-31.

[76] Woolley CS, McEwen BS. Roles of estradiol and progesterone in regulation of hippocampal dendritic spine density during the estrous cycle in the rat. J Comp Neurol 1993;336:293-306.

[77] Klintsova A, Levy WB, Desmond NL. Astrocytic volume fluctuates in the hippocampal CA1 region across the estrous cycle. Brain Res 1995;690:269-74.

[78] Luquin S, Naftolin F, Garcia-Segura LM. Natural fluctuation and gonadal hormone regulation of astrocyte immunoreactivity in dentate gyrus. J Neurobiol 1993;24:913-24.

[79] Cerbai F, Lana D, Nosi D, Petkova-Kirova P, Zecchi S, Brothers HM, et al. The neuron-astrocyte-microglia triad in normal brain ageing and in a model of neuroinflammation in the rat hippocampus. PloS ONE 2012;7:e45250.

[80] Rodriguez K a, Dodds SG, Strong R, Galvan V, Sharp ZD, Buffenstein R. Divergent tissue and sex effects of rapamycin on the proteasome-chaperone network of old mice. Front Mol Neurosci 2014;7:83.

[81] Keith CT, Schreiber SL. PIK-related kinases: DNA repair, recombination, and cell cycle checkpoints. Science 1995;270:50-1.

[82] Vézina C, Kudelski A, Sehgal SN. Rapamycin (AY-22,989), a new antifungal antibiotic. I. Taxonomy of the producing streptomycete and isolation of the active principle. J Antibiot (Tokyo) 1975;28:721-6.

[83] Huang S, Bjornsti MA, Houghton PJ. Rapamycins: mechanism of action and cellular resistance. Cancer Biol Ther 2003;2:222-32.

[84] Yang H, Rudge DG, Koos JD, Vaidialingam B, Yang HJ, Pavletich NP. mTOR kinase structure, mechanism and regulation. Nature 2013;497:217-23.

[85] Hubbard PA, Moody CL, Murali R. Allosteric modulation of Ras and the PI3K/AKT/mTOR pathway: emerging therapeutic opportunities. Front Physiol 2014;5:1-7.

[86] Cafferkey R, Young PR, McLaughlin MM, Bergsma DJ, Koltin Y, Sathe GM, et al. Dominant missense mutations in a novel yeast protein related to mammalian phosphatidylinositol 3-kinase and VPS34 abrogate rapamycin cytotoxicity. Mol Cell Biol 1993;13:6012-23.

[87] Kunz J, Henriquez R, Schneider U, Deuter-Reinhard M, Movva NR, Hall MN. Target of rapamycin in yeast, TOR2, is an essential phosphatidylinositol kinase homolog required for G1 progression. Cell 1993;73:585-96.

[88] Long X, Spycher C, Han ZS, Rose AM, Müller F, Avruch J. TOR deficiency in C. elegans causes developmental arrest and intestinal atrophy by inhibition of mRNA translation. Curr Biol 2002;12:1448-61.

[89] Oldham S. Genetic and biochemical characterization of dTOR, the Drosophila homolog of the target of rapamycin. Genes Dev 2000;14:2689-94.

[90] Fleming A, Rubinsztein DC. Zebrafish as a model to understand autophagy and its role in neurological disease. Biochim Biophys Acta 2011;1812:520-6.

[91] Sarbassov DD, Ali SM, Kim D-H, Guertin DA, Latek RR, Erdjument-Bromage $\mathrm{H}$, et al. Rictor, a novel binding partner of mTOR, defines a rapamycin-insensitive and raptor-independent pathway that regulates the cytoskeleton. Curr Biol 2004;14: 1296-302.

[92] Sabatini DM. mTOR and cancer: insights into a complex relationship. Nat Rev Cancer 2006:6:729-34. 
[93] Laplante M, Sabatini DM. Regulation of mTORC1 and its impact on gene expression at a glance. J Cell Sci 2013;126:1713-19.

[94] Sarbassov DD, Ali SM, Sengupta S, Sheen J-H, Hsu PP, Bagley AF, et al. Prolonged rapamycin treatment inhibits mTORC2 assembly and Akt/PKB. Mol Cell 2006;22:159-68.

[95] Inoki K, Li Y, Xu T, Guan K-L. Rheb GTPase is a direct target of TSC2 GAP activity and regulates mTOR signaling. Genes Dev 2003;17:1829-34.

[96] Sarbassov DD, Guertin DA, Ali SM, Sabatini DM. Phosphorylation and regulation of $\mathrm{Akt} / \mathrm{PKB}$ by the rictormTOR complex. Science 2005;307:1098-101.

[97] Laplante M, Sabatini DM. mTOR signaling in growth control and disease. Cell 2012;149:274-93.

[98] Blommaart EFC, Luiken JJFP, Blommaart PJE, van Woerkom GM, Meijer AJ. Phosphorylation of ribosomal protein $\mathrm{S} 6$ is inhibitory for autophagy in isolated rat hepatocytes. J Biol Chem 1995;270:2320-6.

[99] Hara K, Yonezawa K, Weng Q-P, Kozlowski MT, Belham C, Avruch J. Amino acid sufficiency and mTOR regulate p70 S6 kinase and eIF-4E BP1 through a common effector mechanism. J Biol Chem 1998;273:14484-94.

[100] Fingar DC, Salama S, Tsou C, Harlow E, Blenis J. Mammalian cell size is controlled by mTOR and its downstream targets S6K1 and 4EBP1/eIF4E. Genes Dev 2002;16:1472-87.

[101] Fingar DC, Richardson CJ, Tee AR, Cheatham L, Tsou C, Blenis J. mTOR controls cell cycle progression through its cell growth effectors S6K1 and 4E-BP1/eukaryotic translation initiation factor 4E. Mol Cell Biol 2004;24:200-16.

[102] Nojima H, Tokunaga C, Eguchi S, Oshiro N, Hidayat S, Yoshino $\mathrm{K}$, et al. The mammalian target of rapamycin (mTOR) partner, raptor, binds the mTOR substrates p70 S6 kinase and 4E-BP1 through their TOR signaling (TOS) motif. J Biol Chem 2003;278:15461-4.

[103] Schalm SS, Fingar DC, Sabatini DM, Blenis J. TOS motifmediated raptor binding regulates 4E-BP1 multisite phosphorylation and function. Curr Biol 2003;13:797-806.

[104] Kovacina KS, Park GY, Bae SS, Guzzetta AW, Schaefer E, Birnbaum MJ, et al. Identification of a proline-rich Akt substrate as a 14-3-3 binding partner. J Biol Chem 2003;278:10189-94.

[105] Thedieck K, Polak P, Kim ML, Molle KD, Cohen A, Jenö P, et al. PRAS40 and PRR5-like protein are new mTOR interactors that regulate apoptosis. PloS ONE 2007;2:e1217.

[106] Sancak Y, Thoreen CC, Peterson TR, Lindquist RA, Kang SA, Spooner E, et al. PRAS40 is an insulin-regulated inhibitor of the mTORC1 protein kinase. Mol Cell 2007;25:903-15.

[107] Tee AR, Manning BD, Roux PP, Cantley LC, Blenis J. Tuberous sclerosis complex gene products, tuberin and hamartin, control mTOR signaling by acting as a gtpase-activating protein complex toward rheb. Curr Biol 2003;13:1259-68.

[108] Van Slegtenhorst M, de Hoogt R, Hermans C, Nellist M, Janssen B, Verhoef S, et al. Identification of the tuberous sclerosis gene TSC1 on chromosome 9q34. Science 1997;277:805-8.

[109] Zhang Y, Gao X, Saucedo LJ, Ru B, Edgar BA, Pan D. Rheb is a direct target of the tuberous sclerosis tumour suppressor proteins. Nat Cell Biol 2003;5:578-81.

[110] Ma L, Chen Z, Erdjument-Bromage H, Tempst P, Pandolfi PP. Phosphorylation and functional inactivation of TSC2 by Erk implications for tuberous sclerosis and cancer pathogenesis. Cell 2005;121:179-93.

[111] Corradetti MN, Inoki K, Bardeesy N, DePinho RA, Guan K-L. Regulation of the TSC pathway by LKB1: evidence of a molecular link between tuberous sclerosis complex and PeutzJeghers syndrome. Genes Dev 2004;18:1533-8.

[112] Hong S-P, Leiper FC, Woods A, Carling D, Carlson M. Activation of yeast Snf1 and mammalian AMP-activated protein kinase by upstream kinases. Proc Natl Acad Sci USA 2003;100:8839-43.
[113] Chiu MI, Katz H, Berlin V. RAPT1, a mammalian homolog of yeast Tor, interacts with the FKBP12/rapamycin complex. Proc Natl Acad Sci USA 1994;91:12574-8.

[114] Chen J, Zheng XF, Brown EJ, Schreiber SL. Identification of an $11-\mathrm{kDa}$ FKBP12-rapamycin-binding domain within the 289-kDa FKBP12-rapamycin-associated protein and characterization of a critical serine residue. Proc Natl Acad Sci USA 1995;92:4947-51.

[115] Wang X, Fonseca BD, Tang H, Liu R, Elia A, Clemens MJ, et al. Re-evaluating the roles of proposed modulators of mammalian target of rapamycin complex 1 (mTORC1) signaling. J Biol Chem 2008;283:30482-92.

[116] Qi Q-R, Yang Z-M. Regulation and function of signal transducer and activator of transcription 3. World J Biol Chem 2014;5:231-9.

[117] Kim J-H, Yoon M-S, Chen J. Signal transducer and activator of transcription 3 (STAT3) mediates amino acid inhibition of insulin signaling through serine 727 phosphorylation. J Biol Chem 2009;284:35425-32.

[118] Kortylewski M, Jove R, Yu H. Targeting STAT3 affects melanoma on multiple fronts. Cancer Metastasis Rev 2005;24:315-27.

[119] Horton JD, Goldstein JL, Brown MS. SREBPs: activators of the complete program of cholesterol and fatty acid synthesis in the liver. J Clin Invest 2002;109:1125-31.

[120] Peterson TR, Sengupta SS, Harris TE, Carmack AE, Kang SA, Balderas E, et al. mTOR complex 1 regulates lipin 1 localization to control the SREBP pathway. Cell 2011;146:408-20.

[121] Rosen ED, MacDougald OA. Adipocyte differentiation from the inside out. Nat Rev Mol Cell Biol 2006;7:885-96.

[122] Lefebvre P, Chinetti G, Fruchart J-C, Staels B. Sorting out the roles of PPAR alpha in energy metabolism and vascular homeostasis. J Clin Invest 2006;116:571-80.

[123] Sengupta S, Peterson TR, Laplante M, Oh S, Sabatini DM. mTORC1 controls fasting-induced ketogenesis and its modulation by ageing. Nature 2010;468:1100-4.

[124] Blagosklonny MV. TOR-centric view on insulin resistance and diabetic complications: perspective for endocrinologists and gerontologists. Cell Death Dis 2013;4:e964.

[125] Majmundar AJ, Wong WJ, Simon MC. Hypoxia-inducible factors and the response to hypoxic stress. Mol Cell 2010;40:294-309.

[126] Bar-Peled L, Schweitzer LD, Zoncu R, Sabatini DM. Ragulator is a GEF for the rag GTPases that signal amino acid levels to mTORC1. Cell 2012;150:1196-208.

[127] Sancak Y, Peterson TR, Shaul YD, Lindquist RA, Thoreen CC, Bar-Peled L, et al. The Rag GTPases bind raptor and mediate amino acid signaling to mTORC1. Science 2008;320:1496-501.

[128] Zoncu R, Efeyan A, Sabatini DM. mTOR: from growth signal integration to cancer, diabetes and ageing. Nat Rev Mol Cell Biol 2011;12:21-35.

[129] Singh R, Cuervo AM. Autophagy in the cellular energetic balance. Cell Metab 2011;13:495-504.

[130] Settembre C, Zoncu R, Medina DL, Vetrini F, Erdin S, Erdin S, et al. A lysosome-to-nucleus signalling mechanism senses and regulates the lysosome via mTOR and TFEB. EMBO J 2012;31:1095-108.

[131] Dalle Pezze P, Sonntag AG, Thien A, Prentzell MT, Godel M, Fischer S, et al. A dynamic network model of mTOR signaling reveals TSC-independent mTORC2 regulation. Sci Signal 2012;5:ra25.

[132] Zinzalla V, Stracka D, Oppliger W, Hall MN. Activation of mTORC2 by association with the ribosome. Cell 2011;144:757-68.

[133] Destefano MA, Jacinto E. Regulation of insulin receptor substrate-1 by mTORC2 (mammalian target of rapamycin complex 2). Biochem Soc Trans 2013;41:896-901.

[134] Yu Y, Yoon S-O, Poulogiannis G, Yang Q, Ma XM, Villen J, et al. Phosphoproteomic analysis identifies Grb10 as an mTORC1 substrate that negatively regulates insulin signaling. Science 2011;332:1322-6. 
[135] Guertin DA, Stevens DM, Thoreen CC, Burds AA, Kalaany NY, Moffat J, et al. Ablation in mice of the mTORC components raptor, rictor, or mLST8 reveals that mTORC2 is required for signaling to Akt-FOXO and PKCalpha, but not S6K1. Dev Cell 2006;11:859-71.

[136] Liu P, Guo J, Gan W, Wei W. Dual phosphorylation of Sin1 at T86 and T398 negatively regulates mTORC2 complex integrity and activity. Protein Cell 2014;5:171-7.

[137] Rosner M, Hengstschläger M. Cytoplasmic and nuclear distribution of the protein complexes MTORC1 and MTORC2: rapamycin triggers dephosphorylation and delocalization of the mTORC2 components rictor and sin1. Hum Mol Genet 2008;17:2934-48.

[138] Huang J, Dibble CC, Matsuzaki M, Manning BD. The TSC1-TSC2 complex is required for proper activation of mTOR complex 2. Mol Cell Biol 2008;28:4104-15.

[139] Oh WJ, Wu C, Kim SJ, Facchinetti V, Julien L-A, Finlan M, et al. mTORC2 can associate with ribosomes to promote cotranslational phosphorylation and stability of nascent Akt polypeptide. EMBO J 2010;29:3939-51.

[140] Betz C, Stracka D, Prescianotto-Baschong C, Frieden M, Demaurex N, Hall MN. Feature article: mTOR complex 2-Akt signaling at mitochondria-associated endoplasmic reticulum membranes (MAM) regulates mitochondrial physiology. Proc Natl Acad Sci USA 2013;110:12526-34.

[141] Balcazar N, Sathyamurthy A, Elghazi L, Gould A, Weiss A, Shiojima I, et al. mTORC1 activation regulates beta-cell mass and proliferation by modulation of cyclin D2 synthesis and stability. J Biol Chem 2009;284:7832-42.

[142] Cnop M, Welsh N, Jonas J-C, Jorns A, Lenzen S, Eizirik DL. Mechanisms of pancreatic-cell death in type 1 and type 2 diabetes: many differences, few similarities. Diabetes 2005;54: S97-107.

[143] Maddison LA, Chen W. Nutrient excess stimulates $\beta$-cell neogenesis in zebrafish. Diabetes 2012;61:2517-24.

[144] Donato AJ, Morgan RG, Walker AE, Lesniewski LA. Cellular and molecular biology of aging endothelial cells. J Mol Cell Cardiol 2015.

[145] Blagosklonny MV. Molecular damage in cancer: an argument for mTOR-driven aging. Aging 2011;3:1130-41.

[146] Mabuchi S, Kuroda H, Takahashi R, Sasano T. The PI3K/ $\mathrm{AKT} / \mathrm{mTOR}$ pathway as a therapeutic target in ovarian cancer. Gynecol Oncol 2015;137:173-9.

[147] Zhou H, Huang S. mTOR signaling in cancer cell motility and tumor metastasis. Crit Rev Eukaryot Gene Expr 2010;20:1-16.

[148] Feng Z, Zhang H, Levine AJ, Jin S. The coordinate regulation of the p53 and mTOR pathways in cells. Proc Natl Acad Sci USA 2005;102:8204-9.

[149] Levine AJ, Feng Z, Mak TW, You H, Jin S. Coordination and communication between the p53 and IGF-1-AKT-TOR signal transduction pathways. Genes Dev 2006;20:267-75.

[150] Obata K, Morland SJ, Watson RH, Hitchcock A, ChenevixTrench G, Thomas EJ, et al. Frequent PTEN/MMAC mutations in endometrioid but not serous or mucinous epithelial ovarian tumors. Cancer Res 1998;58:2095-7.

[151] Levine DA, Bogomolniy F, Yee CJ, Lash A, Barakat RR, Borgen PI, et al. Frequent mutation of the PIK3CA gene in ovarian and breast cancers. Clin Cancer Res 2005;11:2875-8.

[152] Philp AJ, Campbell IG, Leet C, Vincan E, Rockman SP, Whitehead RH, et al. The phosphatidylinositol 3'-kinase p85alpha gene is an oncogene in human ovarian and colon tumors. Cancer Res 2001;61:7426-9.

[153] Carpten JD, Faber AL, Horn C, Donoho GP, Briggs SL, Robbins CM, et al. A transforming mutation in the pleckstrin homology domain of AKT1 in cancer. Nature 2007;448:439-44.
[154] Pause A, Belsham GJ, Gingras AC, Donzé O, Lin TA, Lawrence JC, et al. Insulin-dependent stimulation of protein synthesis by phosphorylation of a regulator of $5^{\prime}$-cap function. Nature 1994;371:762-7.

[155] Hay N, Sonenberg N. Upstream and downstream of mTOR. Genes Dev 2004;18:1926-45.

[156] Gingras AC, Raught B, Gygi SP, Niedzwiecka A, Miron M, Burley SK, et al. Hierarchical phosphorylation of the translation inhibitor 4E-BP1. Genes Dev 2001;15:2852-64.

[157] Vivanco I, Sawyers CL. The phosphatidylinositol 3-Kinase AKT pathway in human cancer. Nat Rev Cancer 2002;2:489-501.

[158] Jacinto E, Loewith R, Schmidt A, Lin S, Rüegg MA, Hall A, et al. Mammalian TOR complex 2 controls the actin cytoskeleton and is rapamycin insensitive. Nat Cell Biol 2004;6:1122-8.

[159] Masri J, Bernath A, Martin J, Jo OD, Vartanian R, Funk A, et al. mTORC2 activity is elevated in gliomas and promotes growth and cell motility via overexpression of rictor. Cancer Res 2007;67:11712-20.

[160] Hietakangas V, Cohen SM. TOR complex 2 is needed for cell cycle progression and anchorage-independent growth of MCF7 and PC3 tumor cells. BMC Cancer 2008;8:282.

[161] Inoki K, Corradetti MN, Guan K-L. Dysregulation of the TSCmTOR pathway in human disease. Nat Genet 2005;37:19-24.

[162] Hoeffer CA, Klann E. mTOR signaling: at the crossroads of plasticity, memory and disease. Trends Neurosci 2010;33:67-75.

[163] Slipczuk L, Bekinschtein P, Katche C, Cammarota M, Izquierdo I, Medina JH. BDNF activates mTOR to regulate GluR1 expression required for memory formation. PLoS One 2009;4:e6007.

[164] Majumder S, Caccamo A, Medina DX, Benavides AD, Javors MA, Kraig E, et al. Lifelong rapamycin administration ameliorates agedependent cognitive deficits by reducing IL-1 $\beta$ and enhancing NMDA signaling. Aging Cell 2012;11:326-35.

[165] Halloran J, Hussong SA, Burbank R, Podlutskaya N, Fischer $\mathrm{KE}$, Sloane LB, et al. Chronic inhibition of mammalian target of rapamycin by rapamycin modulates cognitive and noncognitive components of behavior throughout lifespan in mice. Neuroscience 2012;223:102-13.

[166] Costa V, Lugert S, Jagasia R. Role of adult hippocampal neurogenesis in cognition in physiology and disease: pharmacological targets and biomarkers. Handb Exp Pharmacol 2015;228:99-155.

[167] Gage FH. Stem cells of the central nervous system. Curr Opin Neurobiol 1998;8:671-6.

[168] Couillard-Despres S, Iglseder B, Aigner L. Neurogenesis, cellular plasticity and cognition: the impact of stem cells in the adult and aging brain—a mini-review. Gerontology 2011;57: 559-64.

[169] Kempermann G, Kuhn HG, Gage FH. Genetic influence on neurogenesis in the dentate gyrus of adult mice. Proc Natl Acad Sci USA 1997;94:10409-14.

[170] Lazarov O, Mattson MP, Peterson DA, Pimplikar SW, van Praag $\mathrm{H}$. When neurogenesis encounters aging and disease. Trends Neurosci 2010;33:569-79.

[171] Lugert S, Basak O, Knuckles P, Haussler U, Fabel K, Götz M, et al. Quiescent and active hippocampal neural stem cells with distinct morphologies respond selectively to physiological and pathological stimuli and aging. Cell Stem Cell 2010;6:445-56.

[172] Romine J, Gao X, Xu X-M, So KF, Chen J. The proliferation of amplifying neural progenitor cells is impaired in the aging brain and restored by the mTOR pathway activation. Neurobiol Aging 2015;36:1716-26.

[173] Jankovic J. Parkinson's disease: clinical features and diagnosis. J Neurol Neurosurg Psychiatry 2008;79:368-76.

[174] Hetz C, Mollereau B. Disturbance of endoplasmic reticulum proteostasis in neurodegenerative diseases. Nat Rev Neurosci 2014:15:233-49. 
[175] Guo C, Sun L, Chen X, Zhang D. Oxidative stress, mitochondrial damage and neurodegenerative diseases. Neural Regen Res 2013;8:2003-14.

[176] Brasnjevic I, Hof PR, Steinbusch HWM, Schmitz C. Accumulation of nuclear DNA damage or neuron loss: molecular basis for a new approach to understanding selective neuronal vulnerability in neurodegenerative diseases. DNA Repair (Amst) 2008;7:1087-97.

[177] Tain LS, Mortiboys H, Tao RN, Ziviani E, Bandmann O, Whitworth AJ. Rapamycin activation of 4E-BP prevents parkinsonian dopaminergic neuron loss. Nat Neurosci 2009;12:1129-35.

[178] Xu Y, Liu C, Chen S, Ye Y, Guo M, Ren Q, et al. Activation of AMPK and inactivation of Akt result in suppression of mTOR-mediated S6K1 and 4E-BP1 pathways leading to neuronal cell death in in vitro models of Parkinson's disease. Cell Signal 2014;26:1680-9.

[179] Malagelada C, Jin ZH, Jackson-Lewis V, Przedborski S, Greene LA. Rapamycin protects against neuron death in in vitro and in vivo models of Parkinson's disease. J Neurosci 2010;30:1166-75.

[180] McKhann G, Drachman D, Folstein M, Katzman R, Price D, Stadlan EM. Clinical diagnosis of Alzheimer's disease: report of the NINCDS-ADRDA Work Group under the auspices of Department of Health and Human Services Task Force on Alzheimer's Disease. Neurology 1984;34:939-44.

[181] Crews L, Masliah E. Molecular mechanisms of neurodegeneration in Alzheimer's disease. Hum Mol Genet 2010;19:R12-20.

[182] Cuervo AM, Dice JF. Age-related decline in chaperonemediated autophagy. J Biol Chem 2000;275:31505-13.

[183] Spilman P, Podlutskaya N, Hart MJ, Debnath J, Gorostiza O, Bredesen D, et al. Inhibition of mTOR by rapamycin abolishes cognitive deficits and reduces amyloid- $\beta$ levels in a mouse model of Alzheimer's disease. PLoS One 2010;5:e9979.

[184] Majumder S, Richardson A, Strong R, Oddo S. Inducing autophagy by rapamycin before, but not after, the formation of plaques and tangles ameliorates cognitive deficits. PLoS One 2011;6:e25416.

[185] Boxer AL, Miller BL. Clinical features of frontotemporal dementia. Alzheimer Dis Assoc Disord 2005;19(Suppl. 1):S3-6.

[186] Chen-Plotkin AS, Lee VM-Y, Trojanowski JQ. TAR DNAbinding protein 43 in neurodegenerative disease. Nat Rev Neurol 2010;6:211-20.

[187] Wang I-F, Guo B-S, Liu Y-C, Wu C-C, Yang C-H, Tsai K-J, et al. Autophagy activators rescue and alleviate pathogenesis of a mouse model with proteinopathies of the TAR DNA-binding protein 43. Proc Natl Acad Sci USA 2012;109:15024-9.

[188] Trushina E, McMurray CT. Oxidative stress and mitochondrial dysfunction in neurodegenerative diseases. Neuroscience 2007; 145:1233-48.

[189] Sepers MD, Raymond LA. Mechanisms of synaptic dysfunction and excitotoxicity in Huntington's disease. Drug Discov Today 2014;19:990-6.

[190] Floto RA, Sarkar S, Perlstein EO, Kampmann B, Schreiber SL, Rubinsztein DC. Erratum: small molecule enhancers of rapamycin-induced TOR inhibition promote autophagy, reduce toxicity in Huntington's disease models and enhance killing of mycobacteria by macrophages (autophagy). Autophagy 2007;3:620-2.

[191] Ravikumar B, Vacher C, Berger Z, Davies JE, Luo S, Oroz LG, et al. Inhibition of mTOR induces autophagy and reduces toxicity of polyglutamine expansions in fly and mouse models of Huntington disease. Nat Genet 2004;36:585-95.

[192] Harrison DE, Strong R, Sharp ZD, Nelson JF, Astle CM, Flurkey K, et al. Rapamycin fed late in life extends lifespan in genetically heterogeneous mice. Nature 2009;460:392-5.
[193] Villa-Cuesta E, Holmbeck MA, Rand DM. Rapamycin increases mitochondrial efficiency by mtDNA-dependent reprogramming of mitochondrial metabolism in Drosophila. J Cell Sci 2014;127:2282-90.

[194] Bonawitz ND, Chatenay-Lapointe M, Pan Y, Shadel GS. Reduced TOR signaling extends chronological life span via increased respiration and upregulation of mitochondrial gene expression. Cell Metab 2007;5:265-77.

[195] Pan Y, Nishida Y, Wang M, Verdin E. Metabolic regulation, mitochondria and the life-prolonging effect of rapamycin: a mini-review. Gerontology 2012;58:524-30.

[196] Kolosova NG, Muraleva NA, Zhdankina AA, Stefanova NA, Fursova AZ, Blagosklonny MV. Prevention of age-related macular degeneration-like retinopathy by rapamycin in rats. Am J Pathol 2012;181:472-7.

[197] Yang S-B, Tien A-C, Boddupalli G, Xu AW, Jan YN, Jan LY. Rapamycin ameliorates age-dependent obesity associated with increased mTOR signaling in hypothalamic POMC neurons. Neuron 2012;75:425-36.

[198] Lloberas N, Cruzado JM, Franquesa M, Herrero-Fresneda I, Torras J, Alperovich G, et al. Mammalian target of rapamycin pathway blockade slows progression of diabetic kidney disease in rats. J Am Soc Nephrol 2006;17:1395-404.

[199] Keogh A, Richardson M, Ruygrok P, Spratt P, Galbraith A, O'Driscoll G, et al. Sirolimus in de novo heart transplant recipients reduces acute rejection and prevents coronary artery disease at 2 years: a randomized clinical trial. Circulation 2004;110:2694-700.

[200] Blagosklonny MV. Rapalogs in cancer prevention: anti-aging or anticancer? Cancer Biol Ther 2012;13:1349-54.

[201] Garber K. Rapamycin's resurrection: a new way to target the cancer cell cycle. J Natl Cancer Inst 2001;93:1517-19.

[202] Bjornsti M-A, Houghton PJ. The TOR pathway: a target for cancer therapy. Nat Rev Cancer 2004;4:335-48.

[203] Kwitkowski VE, Prowell TM, Ibrahim A, Farrell AT, Justice R, Mitchell SS, et al. FDA approval summary: temsirolimus as treatment for advanced renal cell carcinoma. Oncologist 2010; 15:428-35.

[204] Hudes Carducci M, Tomczak P, Dutcher J, Figlin R, Kapoor A, Staroslawska E, The Global ARCC, G, et al. Temsirolimus, interferon alpha or both for advanced renal cell carcinoma. N Engl J Med 2007;356:2271-81.

[205] Mabuchi S, Altomare DA, Connolly DC, Klein-Szanto A, Litwin S, Hoelzle MK, et al. RAD001 (everolimus) delays tumor onset and progression in a transgenic mouse model of ovarian cancer. Cancer Res 2007;67:2408-13.

[206] Ning YC, Cai GY, Zhuo L, Gao JJ, Dong D, Cui S, et al. Short-term calorie restriction protects against renal senescence of aged rats by increasing autophagic activity and reducing oxidative damage. Mech Ageing Dev 2013;134: $570-9$.

[207] Cuervo AM, Bergamini E, Brunk UT, Dröge W, Ffrench M, Terman A. Autophagy and aging: the importance of maintaining "clean" cells. Autophagy 2005;1:131-40.

[208] Levine B, Klionsky DJ. Development by self-digestion: molecular mechanisms and biological functions of autophagy. Dev Cell 2004;6:463-77.

[209] Rajawat YS, Hilioti Z, Bossis I. Aging: central role for autophagy and the lysosomal degradative system. Ageing Res Rev 2009;8:199-213.

[210] Estep PW, Warner JB, Bulyk ML. Short-term calorie restriction in male mice feminizes gene expression and alters key regulators of conserved aging regulatory pathways. PLoS One 2009;4:e5242. 